\title{
A POLITICAL METHOD OF EVALUATING THE EDUCATION FOR ALL HANDICAPPED CHILDREN ACT OF 1975 AND THE SEVERAL GAPS OF GAP ANALYSIS
}

\author{
William H. Clune* \\ AND \\ Mark H. Van Pelt $\dagger$
}

I

\section{INTRODUCTION}

This article argues that an evaluation of Public Law No. 94-142, the Education for All Handicapped Children Act (EAHCA) ${ }^{1}$ (and by analogy any other social program), should consist of six elements discussed in the following pages: a synthesis of empirical research on the implementation of EAHCA relative to reformist objectives (what happened?); a political explanation of the implementation "gap" revealed in these empirical studies (whose interests were served?); an assessment of how the policy instrument chosen for the EAHCA ("legalization") contributed to the implementation gap (what were the realistic limits of change?); a discussion of the standards appropriate as normative yardsticks against which to evaluate the law (reformist versus politically realistic standards); an overall evaluation of the EAHCA in light of the standards developed in the preceding section; and some recommendations about what should be done now. As a connected whole, these topics comprise a "political method" of social program evaluation, ${ }^{2}$ a method with two essential components: a descriptive idea that implementation is a process of political adjustment among competing interests, and a normative idea that the political interests revealed during implementation must be given some nor-

Copyright (C) 1985 by Law and Contemporary Problems

* Professor, University of Wisconsin Law School.

$\dagger$ J.D. and Ph.D. (Educational Policy Studies) candidate, University of Wisconsin-Madison.

The research for this article was supported by Grant Nos. NIE-G-81-0009 and NIE-G-84-0008 to the Wisconsin Center for Education Research. Helpful comments were received from Jack Coons and most if not all of the participants at the Children With Special Needs Symposium, held at Duke Law School, February 1984. Such support, assistance or approval does not imply agreement with the conclusions of this research.

1. 20 U.S.C. $\$ \S 1400-1461$ (1982) (codifying Pub. L. No. 94-142, 89 Stat. 773 (1975) and subsequent amendments).

2. The basic political model and approach to evaluation used in this article may be found in Clune, A Political Model of Implementation and Implications of the Model for Public Policy, Research, and the Changing Roles of Law and Lawyers, 69 IowA L. REv. 47, 86-95 (1983). 
mative significance. Evaluations which ignore the descriptive fact of political adjustments are usually formalistic, concerning themselves with the meaning of legal language rather than the fates of affected individuals and organizations. ${ }^{3}$ Evaluations which ignore the normative significance of political adjustments fall into either of two antithetical fallacies: the ideological fallacy (or "gap analysis"), which assumes the ethical primacy of reformist objectives, ignoring the ethical claims of competing interests, ${ }^{4}$ or the sociological fallacy, which assumes the ethical primacy of actual behavior. ${ }^{5}$ Evaluations also must be pragmatic. Before judging what has occurred, and before recommending reform, one must develop a theory of the possible. For this reason, the limits of social change through legalization will be discussed in section II $B$.

The two major parts of this article correspond to the two major components of a political evaluation: a descriptive political analysis of the implementation of the EAHCA (provided in part II) and a normative discussion of success, failure, and the need'for reform (provided in part III). Part II offers a description and explanation of what happened during the implementation of the EAHCA (what program adjustments occurred and which political interests were responsible for them). The product of that effort is a picture of implementation as a mosaic of human interests and intentions, a dynamic equilibrium struck from the ethical, economic, political, and organizational goals and resources of the people and organizations concerned with special education. ${ }^{6}$ Part III begins with this political analysis and evaluates what happened in light of it. Looking at special education implementation as a human interaction, the questions are whether it was a constructive interaction and how future intervention should try to change the interaction.

3. Formalistic evaluations may overestimate program success (e.g., by assuming that due process provides a realistic opportunity to be heard simply because there is a legal right), or underestimate program success (e.g., by assuming that a right to a minimum of education is unimportant when in practice advocates can use such a right quite effectively). See discussion of Board of Educ. v. Rowley, 458 U.S. 176 (1982), infra note 188 and accompanying text.

4. Gap studies were the subject of an unpublished speech by Austin Sarat at the annual meeting of the Law and Society Association, June 1983. See Abel, Law as Lag: Inertia as a Social Theory of Law, 80 MICH. L. REv. 785, 786, 795 (1982).

This gap is significant in three ways. See infra notes 189-218 and accompanying text (gap explained descriptively in terms of political adjustments during implementation; examination of role of legalization as policy instrument in producing gap); infra notes 219-230 and accompanying text (uniform negative evaluation implied from gap disputed because of failure to recognize normative significance of competing interests revealed during implementation); infra part III (gap a necessary part of ongoing democratic evaluations because of the need for and inevitability of a counterfactual idealistic perspective, for example, in arguments over the practical meaning of reformist legal language in statutes, court decrees, and administrative rules). In addition, all of section I A, infra, is an empirically grounded description and explanation of the EAHCA implementation gap.

5. See Etzioni, Two Approaches to Organizational Analysis: A Critique and a Suggestion, 5 AD. SCI. Q. $257(1960)$.

6. The set of those affected by a law and concerned enough to make responses and adjustments has been called the "social field." See S. Macaulay, Private Government (Working Paper No. 1983-6, Disputes Processing Research Program, University of Wisconsin Law School) (also forthcoming in the Social Science Research Council Handbook of Law and Social Science); Moore, Law and Social Change: The Semi-Autonomous Social Field As An Appropriate Subject of Study, 7 LAw \& Soc'y REv. 719 (1973). 
II

\section{The Politics of EAHCA Implementation-What Happened AND WHY?}

This part proposes a description and political explanation of EAHCA implementation. In section A, empirical studies of EAHCA implementation are summarized according to outcomes, chronological stages, and procedural mechanisms in the process of special education decisionmaking. It is illustrative of the indelible normativity of law, that one cannot describe the process of implementation without measuring it against some standard, expectation, or norm.?

Section A also begins the political explanation of implementation patterns by suggesting specific, contextual reasons for the adjustments which seem to have occurred at each stage of the process. Section B generalizes on those particularized observations by suggesting a general model of social change through social program implementation (legislation or institutional litigation). ${ }^{8}$ According to this model, change occurs because the law provides a variety of new resources, but change is limited because of the intrinsic limitations of these resources and a variety of countervailing forces. Section B also considers specific strengths and weaknesses of the particular form of legal intervention chosen by the EAHCA: legalization, or proceduralism. ${ }^{9}$ Even under the optimum conditions represented by the EAHCA, that method is found to produce change which is fast and widespread but also shallow and uneven.

\section{A. EAHCA Implementation Summarized: Successes, Failures and Reasons}

Summarizing the implementation of a law centers on a few deceptively simple inquiries. First, what are the requirements set forth by the law? Second, what would the law achieve if it were perfectly implemented according to the standards and expectations of its reformist sponsors? Third, how did outcomes of the implementation process compare with these goals? Finally, to what extent can outcomes of implementation be linked to the chronological sequence of procedures established by the law as a means of achieving the ultimate goals?

7. On the sociological normativity of legal facts, see Clune \& Lindquist, What "Implementation" Isn't: Toward a General Framework for Implementation Research, 1981 WIS. L. REv. 1044, 1114 ; Clune, Courts and Legislators As Arbitrators of Social Change (Book Review), 93 YALE L.J. 763, 770-71 (1984).

8. Some authorities implicitly or explicitly distinguish social program implementation from regulation. Compare E. Bardach, The Implementation Game: What Happens After a Bill Becomes a Law (1977), with E. Bardach \& R. Kagan, Going By the Book (1982). See also Social Program IMPLEMENTATION (W. Williams \& R. Elmore eds. 1976) (implementation seemingly defined as laws involving financial aid or program development). Clune has defined implementation functionally as resources, assistance, and regulation seeking to change preferred behavior, especially of complex organizations. Clune \& Lindquist, supra note 7, at 1072-83; Clune, supra note 2, at 50-51.

9. Proceduralism in education has been a concern of Professors Kirp and Yudof for some time. See Kirp, Proceduralism and Bureaucracy: Due Process in the School Setting, 28 Stan. L. REv. 841, 859-76 (1976); Yudof, Legalization of Dispute Resolution, Distrust of Authority, and Organization Theory: Implementing Due Process for Students in the Public Schools, 1981 WIS. L. REV. 891; see also infra note 215. 
Answers to the third and fourth questions in this sequence suggest that the research has established what usually are problematic causal links between social actions. The data base for this article is not so strong. No randomized experiments have been performed, and there is really no practical way to separate the influence of the EAHCA from other forces in the environment moving in the same direction (state laws, popular attitudes, etc.). Further, the existing studies leave unanswered many questions pertinent to causation issues. For example, not much is known about the reasons for teacher referral decisions, although teachers are the principal decisionmakers in the referral process. Nonetheless, the causation problem is not especially troublesome. The conclusions reached in this section represent a synthesis of a score of extensive, well-constructed implementation studies. The data base cannot be much improved, and any gaps do not prevent the studies from establishing reliable general patterns of implementation.

One final point: keep in mind that, throughout the synthesis of implementation research, the political explanations of the observed patterns are a major concern. In every section dealing with implementation results, questions will be asked about whose interests were served by the particular adjustments discussed. The implementation case studies examined all seem to rely on this form of explanation. Major organizational adjustments are seen as satisfying some set of organizational needs. As will be seen in the case of organizations like schools, which are under a great deal of pressure to do various things, the idea of politically adaptive organizational adjustments is not a bold assumption.

1. The EAHCA Process. The EAHCA requires each state and, in turn, each local education agency (LEA), to identify, locate, and evaluate all handicapped children in all public and private agencies and institutions ${ }^{10}$ and provide them with a free appropriate public education. An LEA must provide written notice to parents in each of the following situations: if it identifies their child as handicapped, evaluates the child for determination of a handicapping condition, proposes to change the child's identification or evaluation, refuses to initially identify and evaluate, or subsequently refuses to reidentify and reevaluate the child." ${ }^{1}$ The LEA must receive the parents' consent for a preplacement evaluation. ${ }^{12}$

Children who are referred ${ }^{13}$ must be evaluated before they are placed in any special education program. ${ }^{14}$ The evaluation must be administered by a multidisciplinary team (M-Team) in the child's native language or mode of communication using at least two valid, correctly administered procedures,

10. 20 U.S.C. $\S \S 1412(2)(C), 1414(a)(1)(A)(1982)$.

11. Id. $\$ 1415(\mathrm{~b})(\mathrm{l})(\mathrm{C})(1982)$.

12. 34 C.F.R. $\$ 300.504$ (b)(1)(i) (1984).

13. EAHCA and its implementing regulations do not provide explicit guidelines regarding the initial referral.

14. 20 U.S.C. $§ 1412(5)(C)$ (1982); 34 C.F.R. $\S \S 300.531-.532$ (1984). 
including at least one procedure that is not a general IQ test. ${ }^{15}$ Assessments must cover all areas of suspected disability ${ }^{16}$ and may not be racially or culturally discriminatory. ${ }^{17}$ Placement decisions should not be based on tests alone, but should include at least one other evaluation source, such as a teacher's observation of the child's classroom performance. ${ }^{18}$ Children who are placed after the M-Team determines that they have a special education need must be reevaluated at least every three years to insure that they are receiving the appropriate education resources. ${ }^{19}$ Each state's annual program plan must include a comprehensive system of personnel development which insures that education agency personnel, as well as parents and volunteers, receive inservice training which will, among other things, assist them in identifying and evaluating children with special educational needs. ${ }^{20}$

Once an education agency determines that a child has a handicapping condition within the meaning of the EAHCA, it must develop an individualized education program (IEP) ${ }^{21}$ for that child. The IEP should be developed at a meeting which includes a representative of the education agency who is qualified to provide or supervise special education, the child's teacher, the parents or guardian of the child, and, where appropriate, the child. ${ }^{22}$ The education agency must provide adequate notice of the meeting to insure that the parents have the opportunity to attend and the meeting must occur at a convenient time and place. ${ }^{23}$ The child's IEP must be implemented in the least restrictive environment for that child; that is, the child should be mainstreamed to the fullest possible extent. ${ }^{24}$

In the event that parents are dissatisfied with this process, they may present complaints to the LEA "with respect to any matter relating to the identification, evaluation, or educational placement of the child, or the provision of a free appropriate public education to such child."25 Whenever the LEA receives such a complaint, the parents (or guardian) of the child shall receive the opportunity to have an impartial due process hearing conducted either by the State Education Agency (SEA), LEA, or another state authority, as determined by the state. ${ }^{26}$ The parents are accorded specific hearing

15. 20 U.S.C. $\S 1412(5)(C)(1982) ; 34$ C.F.R. $\S 300.532(a)-(e)$ (1984).

16. 34 C.F.R. $\$ 300.532$ (f) (1984).

17. Id. $\S 300.530(\mathrm{~b})(1984)$.

18. 34 C.F.R. $\$ 300.533(\mathrm{a})(1)-(3)$ (1984). The regulations contain additional detailed requirements for $\mathrm{M}$-Teams with respect to evaluating a child suspected of having a specific learning disability, including provisions for additional M-Team members, classroom observations, a special written report, and a specific finding that the child's disability is not actually another type of disability. See id. $\S \S 300.540-.543$ (1983).

19. Id. $\S 300.534(\mathrm{~b})(1984)$.

20. 20 U.S.C. $\S 1413(\mathrm{a})(3)(1982) ; 34$ C.F.R. $\S 300.382$ (1984).

21. 20 U.S.C. $\$ 1401(19)(1982)$.

22. Id.

23. 34 C.F.R. $\$ 300.345$ (a)-(b) (1984).

24. 20 U.S.C. $\$ 1412(5)(B)(1982)$.

25. Id. $\$ 1415$ (b)(1)(E) (1982). This right extends to the child's parents or guardian. LEA's may initiate the hearing process in the event that, for whatever reason, no parental consent is provided for the child's evaluation or initial placement. 34 C.F.R. $\$ 300.504$ (c) (1984).

26. 20 U.S.C. $\$ 1415$ (b)(2) (1982). 
rights, ${ }^{27}$ a timely response to their complaint, ${ }^{28}$ and an impartial and independent review of the hearing at the state level if the original hearing was conducted below the state agency level. ${ }^{29}$ When these administrative procedures are exhausted, ${ }^{30}$ any aggrieved party has the right to a civil action with respect to the original complaint and may bring that action in any state court of competent jurisdiction or in a U.S. district court. The court 1) reviews the administrative record, 2) hears additional evidence at the request of either party, and 3) on the preponderance of the evidence, "grant[s] such relief as the court determines is appropriate."31 In addition to establishing this elaborate procedural mechanism designed to ensure that each handicapped child receives an appropriate free public education, the EAHCA also establishes a funding mechanism to help states cope with the new costs of special education.

2. Implementational Assumptions and Reformist Purposes. Congress had to make many assumptions about how this sequence of elaborate procedural mechanisms could fully achieve the ambitious, even monumental, reformist objective that all handicapped children were to receive a free, appropriate education (and that no nonhandicapped children were to accidentally end up in a special education program). First, Congress assumed an operational environment in which relatively few referral and assessment errors would occur either as a result of inadequate knowledge within the system or as a result of inherently inadequate testing mechanisms. Although Congress knew that teachers were not entirely prepared to implement the Act, ${ }^{32}$ it assumed that the evaluation process, through better trained personnel and nondiscriminatory multiple assessment procedures, would screen the errors generated through teacher referral. Gradually, teacher inservice programs would increase referring teachers' knowledge of special education needs, thereby increasing the accuracy of the referrals and reducing the need for such screening and the workload on the assessment staff. ${ }^{33}$

27. Id. $\$ 1415$ (d) (1982). The parties involved in such a hearing may: l) be accompanied and advised by counsel; 2) be accompanied by persons with special knowledge or training with respect to special education; 3) present evidence; 4) confront, cross-examine, and compel attendance of witnesses; 5) have a written or electronic verbatim record of the hearing; and 6) have the right to written findings of facts and a copy of the decision. A final due process hearing regarding the complaint must be conducted within forty-five days of receipt of request of the hearing. In the event that the initial hearing was conducted below the SEA level, "any party aggrieved by the findings and decision rendered in such a hearing may appeal to the State educational agency which shall conduct an impartial review of such hearing. The officer conducting such review shall make an independent decision upon completion of such review." Id. $\$ 1415$ (c) (1982). The same rights apply to the parties if the original hearing occurred at a level below the SEA and one of the parties appeals the result of the hearing to the SEA.

28. 34 C.F.R. § $300.512(\mathrm{a})(1984)$.

29. 20 U.S.C. $\$ 1415(\mathrm{c})(1982)$.

30. Id. $\$ 1415(\mathrm{e})(1)(1982)$.

31. Id. $\S 1415(\mathrm{e})(2)(1982)$.

32. S. ReP. No. 168, 94 th Cong., 1 st Sess. 33, reprinted in 1975 U.S. Code Cong. \& AD. News 1425,1457 .

33. 20 U.S.C. $\$ 1400(b)(7)(1982)$. 
Second, Congress believed the IEP procedure was "a way to provide parent involvement and protection to assure that appropriate services are provided to a handicapped child."34 Although it did not explicitly so state, Congress clearly assumed that educators would not on their own maximize the educational potential of each child. While Congress saw the IEP conference as the culmination of the identification and evaluation process, it simultaneously expected that parents would utilize it "as an extension of the procedural protections guaranteed under existing law to parents of handicapped children. . . ."35

Third, Congress assumed that the due process provisions would make it easier for parents to take successful action against uncooperative districts. In contrast to court procedures, the EAHCA's due process provisions were assumed to be relatively informal, inexpensive, quick, and substantively oriented. ${ }^{36}$ A procedural mechanism with these characteristics supposedly would lead to more systematic pressure on school systems, put handicapped children on an educational par with nonhandicapped students, and lead to uniformity of treatment among handicapped children. ${ }^{37}$ Further, advocates

34. S. Rep. No. 168, 94th Cong., 1st Sess. 12 (1975), reprinted in 1975 U.S. Code Cong. \& AD. News 1425, 1436; see also H.R. Rep. No. 332, 94th Cong., 1st Sess. 13 (1975); S. Rep. No. 168, 94th Cong., Ist Sess. 11 (1975), reprinted in 1975 U.S. Code Cong. \& AD. News 1425, 1435 (adequate involvement).

35. S. REP. No. 168, 94th Cong., lst Sess. 11 (1975), reprinted in 1975 U.S. Code Cong. \& AD. News $1425,1435$.

36. The Act's legislative history contains numerous statements assuming that the due process provisions would make life easier for parents and schools. See, e.g., S. REP. No. 168, 94th Cong., 1 st Sess. 9 (1975), reprinted in 1975 U.S. Code ConG. \& AD. News 1425, 1433 ("It should not . . . be necessary for parents throughout the country to continue utilizing the courts to assure themselves a remedy."). Several senators sponsoring the EAHCA expressed views that the due process requirements would remove the difficulties that the court system presented to most parents trying to get an appropriate education for their children. "It is part of the rhythm of life in this country, an unconscious assumption, that our children will be educated. So should it be for the handicapped child and his parents. It must not be, for them, a court battle." 121 Cong. REc. 37,411 (1975) (remarks of Senator Stafford); see also 121 Cong. Rec. 37,416 (1975) (remarks by Senator Williams) (stressing the importance of a prompt hearing process in order to avoid setbacks to the child's education). Indeed, the classic, pre-EAHCA federal court decisions implemented due process requirements because the courts also thought that due process would provide a more facilitative shadow under which to bargain than that presented by the courts. See Pennsylvania Ass'n for Retarded Citizens v. Pennsylvania, 334 F. Supp. 1257 (E.D. Pa. 1971), enforced, 343 F. Supp. 279 (E.D. Pa. 1972); Mills v. Board of Educ., 348 F. Supp. 866 (D.D.C. 1972). The EAHCA, it should be noted, does not provide substantive standards to decide placement disputes. Indeed, one congressional report specifically noted that inasmuch as each handicapped child is unique, the Act was meant to give local school districts a certain degree of flexibility in balancing state, local, and parental interests while providing the child with an appropriate education. H.R. REP. No. 332, 94th Cong., Ist Sess. 16 (1975). In this respect, it is clear that Congress-if not the handicapped advocacy community-wanted to leave education agencies with a certain amount of discretion to determine what was an appropriate education for each child. However, there are also many statements in the reports and the Congressional Record indicating that the Congressional goal was to assure the maximization of each handicapped child's potential, thus implying that Congress did have a significant scale in mind against which substantive standards should be measured. See, e.g., H.R. ReP. No. 332, 94 th Cong., Ist Sess. 19 (1975); see also Neal \& Kirp, The Allure of Legalization Reconsidered: The Case of Special Education, LAw \& ConTEMP. Probs, Winter 1985, at 63.

37. See L. Lynn, The Emerging System for Educating Handicapped Children 30-31 (Oct. 29 , 1981) (unpublished manuscript) (proponents of the EAHCA hoped that the law would provide the handicapped with the same level of services and the same respect from teachers and administrators 
hoped that results in individual cases would be followed across the board, producing a general pattern of compliance.

Finally, Congress knew that the EAHCA created an expensive compliance burden for the states. ${ }^{38}$ Some of the changes, such as changes in organizational routines and attitudes, would entail nonmonetary costs. Others, such as individualized education, the development of new programs, and adequate and timely evaluations, would require an infusion of new financial resources. As to these increased costs, the EAHCA assumed that Congress would fulfill the financial side of the bargain it had made in seeking state support for the legislation. ${ }^{39}$

3. EAHCA Implementation Synopsis. Having laid out the essentials of the formal EAHCA process and the operational assumptions implicit in its reformist objectives, the next step is an examination of EAHCA implementation developments and the reasons for them.

a. Reformist objectives and the bottom line. Special education reformists expected the EAHCA to fulfill four broad objectives. First, they wanted to ensure that each child with a handicapping condition received an appropriate education. Second, the reformists wanted to increase the resources available for special education, particularly resources coming from the federal government. Third, reformists wanted each handicapped child, in the progressive education tradition, ${ }^{40}$ to have individualized educational services. Finally, the special education advocates wanted handicapped children mainstreamed to the maximum extent possible. The following briefly summarizes what is known about EAHCA implementation in light of these objectives. ${ }^{41}$

that regular education students received). For example, two child advocacy groups who led the way in passage of the EAHCA, the Children's Defense Fund and the California Rural Legal Assistance Foundation, were heavily involved in litigation activities and did not believe that the LEAs were likely to comply with the law without the due process legalism. One advocate involved in the process said: "We felt we couldn't trust the professionals so we wanted a procedure whereby the parents could say, I don't want my child classified as mentally retarded. . . . We knew that was the only way that the power of the school districts could be offset . . . . We knew that just the presence of such a [due process] system would force the district to play more honestly." See, e.g., Neal \& Kirp, supra note 36, at 74 .

38. See, e.g., H.R. ReP. No. 332, 94th Cong., 1st Sess. 7, 23 (1975); S. REP. No. 168, 94th Cong., 1 st Sess. 7 (1975), reprinted in 1975 U.S Code Conc. \& AD. NEws 1425, 1431; see also Tweedie, The Politics of Legalization in Special Education Reform, in SPEcial Education Policies: Their History, IMPLEMENTATION, AND FiNANCE 48, 59 (1983).

39. The Act's language indicates that, as of 1982, Congress expected to fund a significant proportion of the total excess cost of special education. 20 U.S.C. $\$ 1411(\mathrm{a})(1)(\mathrm{B})(\mathrm{v})(1982)$. However, federal funding never has risen to more than fifteen percent of the total cost of special education, and appropriations always have been far less than authorizations under the Act. See Magnetti, Some Potential Incentives of Special Education Funding Practices, in Placing Children in Special Education: A STRATEGY FOR EQUITY 300, 315 (1982); Neal \& Kirp, supra note 36, at 80-81 (noting the growing gap between authorizations and appropriations for the EAHCA).

40. For a discussion of the progressive tradition in American education and its individualized approach to education, see L. Cremin, The Transformation of the School (1961).

41. This analysis relies on the best available data. Despite the many studies of EAHCA implementation, a great deal remains unknown. Some of the gap in our knowledge is the result of unasked questions; the rest is the result of questions which were asked at only one point in the Act's implementation cycle. In the latter case, the data do not provide a dynamic picture of the implementation 
(i) Appropriate education. Prior to the passage of the EAHCA, many handicapped children were excluded from school because the services they required were too costly and too institutionally difficult for public schools to provide, ${ }^{42}$ even though the children could benefit from educational services. ${ }^{43}$ Estimates of the number of children denied educational services in the 1970's ranged from one to two million children. ${ }^{44}$ Congress accepted the one million figure in justifying passage of the EAHCA in 1975.45 Congress required LEA's and SEA's to develop Child Find procedures to rectify this problem. Although it appears that these estimates of excluded children were too high, ${ }^{46}$ school districts and SEA's rapidly implemented Child Find procedures under the impetus of the EAHCA. In 1976 the Department of Health, Education and Welfare's (HEW) Office of Civil Rights (OCR) estimated that 463,000 children remained excluded from school,47 by 1980 OCR estimated that the number of unserved children had dropped to $22,600 .{ }^{48}$ Other agencies, while

process. It is unlikely, however, that there will be rnany more detailed studies of EAHCA implementation. What we have now is all that we are likely to have (at least sponsored by the government) for some time to come. See Education of the Handicapped ACt Amendments of 1983, H.R. REP. No. 410, 98th Cong., 1st Sess. 24, reprinted in 1984 U.S. Code ConG. \& AD. News 2088, 2111 (noting that emphasis in EAHCA research should shift away from implementation studies to studies of new technologies for improving special education methodologies, instructional environments, and curricula).

42. See generally T. Cottle, Barred from School 50-69 (1976) (describing inadequate public resources and institutional response to handicapped children); S. Sarason \& J. Doris, Educational Handicap, Public Policy, and Social History 360-63 (1979) (on institutional barriers to mainstreaming retarded children). On the additional costs of special education, see J. KakALIK, W. FURRY, M. Thomas \& M. Carney, The Cost of Special Education 5 (1981) (Rand Note N-1792-ED), and Hartman, Projecting Special Education Costs, in Special Education Policies: Their History, ImpleMENTATION AND FinANCE 241 (1983).

43. Educators consider as educable virtually all handicapped children. See e.g., D. HaLLAHAN \& J. Kauffman, Exceptional Children 413-15 (1978); Baer, A Hung Jury and a Scottish Verdict: "Not Proven," 1 Analysis \& Intervention in Developmental Disabilities 91 (1981); Favell, Risley, Wolfe, Riddle \& Rassmussen, Limits of Habilitation: How Can We Identify Them and How Can We Change Them?, 1 Analysis \& Intervention in Developmental Disabilities 37 (1981).

44. See Neal \& Kirp, supra note 36 , at 67 (citing 1970 estimate of two million excluded handicapped children).

45. 20 U.S.C. $\$ 1400(\mathrm{~b})(4)(1982)$.

46. See Kirp, Buss \& Kuriloff, Legal Reform of Special Education: Empirical Studies and Procedural Proposals, 62 Calif. L. Rev. 40, 63 (1974) (child find activities as a result of the consent decree in Pennsylvania Ass'n for Retarded Citizens v. Pennsylvania, 343 F. Supp. 279 (E.D. Pa. 1972), turn up "far fewer" excluded children in Pennsylvania than advocates or the state expected); C. Brown, Special Education for Minority and Low Income Children 3 (1983) (unpublished manuscript) (a 1976 Office of Civil Rights (OCR) survey estimated that 463,000 handicapped were excluded from school nationwide, less than half of what Congress had estimated). The fact that only fourteen states had special education legislation in 1970, but forty-six had some form of special education legislation by 1974, as well as the fact that state funding of special education more than doubled between 1972 and 1974 indicates that the overestimates of excluded handicapped children may have resulted from data lagging behind state action. See Gov't Accounting Office, Disparities Still Exist in Who Gets Special Education 3 (Sept. 30, 1981) (GA 1.13 IPE-81-1).

47. See Brown, supra note 46 , at 3 .

48. Id. The Government Accounting Office also has concluded that there are essentially no handicapped children excluded from public schools. Gov't Accounting Office, supra note 46, at 77. However, some caution should be observed in working with these estimates of excluded and unserved children. Though states uniformly indicate that they have identified all excluded children (that is, all first priority children under the EAHCA), the states also privately acknowledge that their EAHCA compliance is pro forma, and that they do not really know how many children remain excluded. M. Thomas, State Allocation and Management of PL 94-142 Funds 21 -22 (Sept. 1980) 
unwilling or unable to make such a precise estimate, concurred in the finding that, by 1980 , few children in need of special education services remained out of school.49 At the same time that the number of unserved children plummeted, the number of children classified as handicapped and served by the schools grew sharply. In 1966, approximately 2.1 million children received special education services. ${ }^{50}$ By $1981-82$, that number had risen to 4.2 million. ${ }^{51}$

The evidence on the number of children receiving an appropriate placement is not as clear as the evidence on complete exclusion. ${ }^{52}$ If all handicapped children were appropriately placed, there would be no appreciable differences in the rates at which various ethnic groups are placed in special education programs. ${ }^{53}$ Yet black children are placed differently than white children. ${ }^{54}$ Disproportional placement is especially noticeable in the educable mentally retarded (EMR) and learning disabled (LD) categories. ${ }^{55}$ Differential classification into EMR and LD is seen as a problem because of the self-

(Rand Note N-1561-ED). Indeed, some states statutorily exclude children under age six and over age eighteen who, if excluded in other states, would be illegally excluded.

49. Gov't Accounting Office, supra note 46 , at 43; see also A. Wright, R. Cooperstein, E. Renneker \& C. Padilla, Local Implementation of PL 94-142: Final Report of a Longitudinal Study 17 (1982) (SRI International, Menlo Park, Calif., Project No. 7124) (a longitudinal case study consisting of interviews of parents, special education teachers, special and regular education administrators, principals, psychologists, vocational educational personnel, and representatives of human service agencies conducted over a four-year period at sixteen local education agencies of varying sizes in nine states finding few excluded children over a four-year period of Child Find activities, despite complete implementation of the Child Find legalism) [hereinafter cited as SRI FINAL].

50. R. Mackie, Special Education in the United States: Statistics 1948-1966, 36 (1969).

51. United States Department of Edugation, Fifth Annual Report to Congress on the Implementation of Public Law 94-142: The Education for All Handicapped Children Act 2 (1983) [hereinafter cited as Fifth ANNUAl Report].

52. Inasmuch as it is difficult to get professional agreement on what "appropriate" education means, we note that we are using the term simply in the sense that a child receiving an appropriate education is getting a reasonably fair share of resources which are used to educate the child in a reasonable way.

53. See Designs for Change, Caught in the Web: Misplaced Children in Chicago's Classes FOR THE Mentally Retarded 34 \& n.110 (1982) (no more than 1.25 percent of any ethnic group should be considered mentally retarded) [hereinafter cited as Designs for Change]; D. Hallahan \& J. KaUfFMAN, supra note 43 , at 44 (some experts believe only about one percent of the population would be considered mentally retarded if adaptive behavior is considered).

54. Gov't Accounting OfFice, supra note 46, at 33-34 (data from an OCR Special Education Survey indicate that in 1978, 5.9 percent of white children, 5.8 percent of Hispanic children, and 8.4 percent of black children participated in educable mentally retarded (EMR), trainable mentally retarded, severely emotionally disturbed, learning disabled (LD), and speech impaired programs).

55. See id. at 61-62 (disproportional EMR placements for black children; overclassified as EMR and underclassified as LD); Designs for CHANGE, supra note 53, at 58 (black children are disproportionately placed in EMR programs in the principal U.S. urban areas, such as New York, Chicago, Los Angeles, Philadelphia, Detroit, and Houston); Finn, Patterns in Special Education Placement as Revealed by the OCR Surveys, in Placing Children in Special Education: A Strategy for Equity 322, 364-66 (1982) (indicating that, for example, in 1978-79, an OCR survey found 1.17 percent of the nonminority students in New York were in EMR programs, compared to 7.13 percent of the black student population; in Alabama, the percentages were 2.07 percent nonminority, 9.48 percent black; in Indiana, 1.5 percent nonminority, 12.04 percent black; in Kentucky, 2.55 percent nonminority, 7.60 percent black).

Finn's analysis also found that the 1978-79 OCR survey indicated great variation in learning disabilities placement rates, as the table below indicates. 
fulfilling effect of the global EMR label versus the "specific problem" connotation associated with LD.

Although these data at least raise the possibility that racial discrimination is a factor in placing children, they also may be explained by etiology, regional variation, or an effort on the part of schools to provide children with more resources and attention. ${ }^{56}$ Although local instances of racial discrimination in special education placement occur, ${ }^{57}$ many uncertainties remain in determining either the extent to which racial discrimination skews local placement rates or the system's potential for systematic misplacement on the basis of race. 58

Even so, it would be surprising if there were not some measure of racial disproportion in special education. Special education has been historically identified with cultural bias; it began as a means of ridding schools of "lockstep laggards," who usually came from among the poor immigrant population. ${ }^{59}$ To some extent special education still performs this institutional function. Nonetheless, despite the uncertainties in the data, there is at least some

Average Percent of Enrollment Classified As Learning Disabled

\begin{tabular}{lrr} 
State & Minority & White \\
\cline { 2 - 3 } N.Y. & 1.79 & 1.16 \\
Pa. & 3.93 & 1.40 \\
Mo. & 3.90 & 3.47 \\
Texas & 8.31 & 3.76 \\
lowa & 15.53 & 4.18 \\
Kansas & 18.08 & 2.28 \\
Minn. & 4.82 & 3.48 \\
Ohio & 2.21 & 1.96 \\
Wis. & 1.77 & 2.23 \\
Calif. & 3.01 & 2.93
\end{tabular}

Id. at $358-60$.

56. Gov't Accounting Office, supra note 46, at 63.

57. See, e.g., Designs for Change, supra note 53, at ix-x (noting lawsuits involving Chicago school system); Larry P. v. Riles, 495 F. Supp. 926 (N.D. Cal. 1979) (action in California challenging classification system as discriminatory).

58. See Applied Management Sciences, A Study to Evaluate Procedures Undertaken to Prevent Erroneous Classification of Handicapped Children: Executive Summary ll (1983) (Dept. of Educ. Contract No. 300-79-0669) (study involving a 1980 representative sample of 100 school districts including a random sample of over 400 schools and 7,000 school personnel which produced analysis of administrative records, self-administered questionnaire responses, and personal interviews and noted that while the aggregate result tends to show equality of treatment and outcomes, many factors, including subjective evaluations by teachers, race of the teachers, variations in testing instruments, and the like have a significant impact at the local level) (hereinafter APPLIED Management Sciences]. All of these studies provide us with many more questions than answers. For example, we have been unable to find any studies which correlate by ethnic background the incidence of placement of children and the staff persons who refer, assess, and place them. For another example, we do not know if black children are more likely to be referred for special education by white teachers than black teachers, or what effect the race of the assessing professionals has on assessment results. The Applied Management Sciences study has indicated that teachers may view minority students as more likely to require special educational services than nonminority students, but that minorities are proportionally overrepresented among special education teachers. The study, however, does not indicate in what direction the racial considerations may work at the various stages of referral, assessment, and placement. See id. at 10-11.

59. See, e.g., Lazerson, The Origins of Special Education, in Special. Education Policies: Their History, Implementation and Finance 15, 16-21 (J. Chambers \& W. Hartman eds. 1983). 
indication that disproportional placement rates are improving. ${ }^{60}$

Apart from variance along ethnic lines, the overall improvement in the provision of appropriate special education services is tempered by significant local variations in the rate of special education placements. For example, a May 1979 report by the Inspector General for HEW stated that diagnostic practices vary enough that "children classified as handicapped in one district may be regarded as 'behavior problems' in another."61 Some districts with high educational standards reportedly identified children as handicapped who would not even be considered to have learning problems in other districts. ${ }^{62}$ The Government Accounting Office (GAO) in early 1980 found significant variability in how states determined that children were speech impaired. ${ }^{63}$ At least in the early years of implementation, it appeared that state eligibility criteria, which in fact determine whether a child is "handicapped" under federal law, varied in their degree of ambiguity and comprehensiveness. For example, in 1977, thirty states had definitions of mental retardation inconsistent with the EAHCA definition. ${ }^{64}$ In 1979-80 the ranges of children identified at the state level as mentally retarded, emotionally disturbed, or learning disabled were 0.63 to 4 percent, 0.10 to 3 percent, and 0.83 to 5.2 percent respectively. ${ }^{65}$ The range of variation had changed little by 1981-82.66

In sum, there has been a sharp rise in the number of children who are receiving an appropriate, or at least a more appropriate, education. Within that rising trend, however, there is a wide band of variation in placement outcomes which may be the result of ethnic, geographic, and resource factors.

(ii) Resources. Just as there has been a dramatic improvement in the reach of special education, there has been a significant increase in the resources available for special education services. For example, in 1966, the total expenditures for the "excess cost" of special education programs was $\$ 680$ million. 67 In 1972 , the excess cost expenditures had risen to $\$ 2.7$ billion. ${ }^{68}$ By 1978, that figure had grown to an estimated $\$ 7$ billion, ${ }^{69}$ and a comparable figure today may well be in excess of $\$ 10$ billion. ${ }^{70}$ The number of special education teachers and other staff employed to serve handicapped

60. See Applied Management Sciences, supra note 58, at 10.

61. Gov't Accounting Office, supra note 46, at 69.

62. Id.

63. Id. at $69-70$.

64. Id. at 72 .

65. Id. at 71 .

66. See Fifth Annual Report, supra note 51, at 70-71 (consider in particular the 1981-82/197980 "percent change in number served" column in the tables that appear therein).

67. 2 Issues in the Classification of Children 442 (N. Hobbs ed. 1975).

68. G. Brewer \& J. Kakalik, Handicapped Children: Strategies for Improving Services 392-93 (1979).

69. J. Kakalik, W. Furry, M. Thomas \& M. Carney, supra note 42, at 5.

70. Fifth ANnual RePort, supra note 51 , at $\mathrm{xvi}, 90$ (the $\$ 10$ billion figure is estimated by multiplying the total number of handicapped 6-year-old children currently served times the average excess cost figure provided in the text for special education services, and then making a conservative adjustment for inflation); see also Hartman, Projecting Special Education Costs, in Special Education Policies: Their History, Implementation, and Finance 241, 283 (1983) (1980-81 cost estimate for special education services was $\$ 9$ billion, with range of probable costs from $\$ 7.3$ to $\$ 12.4$ billion). 
students has also grown sharply. In 1976-77, there were 179,804 special education teachers and 151,649 school staff employed to serve handicapped children. By 1980-81 those numbers had increased to 232,627 and 207,384 respectively. ${ }^{71}$ Of course, the availability of funds and staff, just as the availability of special education services generally, varies significantly at the local level. ${ }^{72}$

(iii) Individualized education. While the EAHCA also sought to ensure that each handicapped child received an individualized education program, it is not at all clear that this objective has been met. Educators have achieved almost total compliance with the procedural mechanism designed to produce individualized programs, the Act's IEP requirement. ${ }^{73}$ In achieving paperwork compliance, however, educators have reduced the paperwork burden by such devices as standardized educational objectives and standardized IEP checklists. Although such methods technically violate the $\operatorname{law}^{74}$ and undermine the ideal of individualization, they save time and may permit the staff to devote more time to more important requirements, such as the IEP conference. ${ }^{75}$ In general, LEA's have refined and streamlined their IEP process, particularly by broadening the short term objectives they write into each IEP. ${ }^{76}$ Thus, LEA's have reached full compliance by reacting pragmatically to

71. Fifth AnNual Report, supra note 51, at 100-01.

72. See, e.g., id. at 112-13 (showing wide variation among states in pupil teacher ratios for various handicapping conditions); M. TномAs, supra note 48, at 5-22 (noting variability in special education funding at local level); Magnetti, supra note 39, at 300 (noting variability in local funding pattern). One study has stressed that it is impossible to overemphasize the importance of funding to the provision of appropriate educational services for the handicapped. SRI Final, supra note 49, at 157; see also Stark, Tragic Choices in Special Education: The Effect of Scarce Resources on the Implementation of Pub. L. No. 94-142, 14 CoNN. L. REv, 477 (1982) (discussing the triage decisions states must make in allocating services to children under conditions of insufficient resources).

73. J. Pyecha, J. Cox, L. Conaway, D. DeWitt, D. Drummond, A. Hocutt, J. Jaffe, M. Kalt, C. Lane, J. Pelosi \& R. Weigerink, A National Survey of Individualized Education Programs (IEPs) for Handicapped Children: Volume I, Executive Summary of Methodology and Major Findings 6 (1980) (Research Triangle Institute, Durham, N.C.; ERIC Doc. No. ED 199 970) (a study of IEPs created in 1978-79 for 2,657 students from 507 public schools in 208 school districts in 42 states) [hereinafter cited as A National Survey of IEPs: Vol. I]. Yet, there are some groups for whom initial IEP's frequently are not generated. J. Pyecha, J. Palmour \& L. Ward, A Study of the Implementation of P.L. 94-142 for Handicapped Migrant Children: Final Report 20-21 (1980) (Research Triangle Institute, Durham, N.C., ERIC Doc. No. ED 199976) (data not good enough to draw conclusive findings but does indicate that classification and IEP generation varies a great deal for migrant children as they move from one school to the next; IEP's generated less frequently for migrant children). It would not be surprising to find similar problems of IEP generation to be especially acute for inner city children, who tend to move a great deal within school districts and are likely, as a result, to slip through the cracks more easily than children who are less frequently mobile.

74. The IEP must be developed at the IEP meeting. 20 U.S.C. $\$ 1401$ (19) (1982). To the extent that teachers pre-form the IEP, they violate the technical mandate of the EAHCA.

75. See M. Knapp, M. Stearns, B. Turnbull, J. David \& S. Peterson, Cumulative Effects of Federal Education Policies on Schools and Districts 62 (1983) (SRI International, Menlo Park, Calif., SRI Project 3590) (1982 interview case study of 900 school staff members in 20 school districts in 8 states, involving 81 elementary schools and 25 high schools) [hereinafter referred to as CUMULATIVE EFFECTS].

76. SRI FINAL, supra note 49, at 34-37. Apparently, some education agencies tried streamlining to the extent that they did not bother to develop IEP's for some children before they placed those children. In January 1981, the Secretary of Education reiterated that IEP objectives had to be written before placement occurred. The move toward permissibly broader short term objectives may be a tacit recognition by the Department of Education that near-perfect IEP compliance will not occur 
the paperwork burden, but it is not clear that the IEP process has led to an increase in the amount of individualized instruction. ${ }^{77}$

(iv) Mainstreaming. Before the EAHCA, it was a common practice to permit handicapped children to participate in regular classrooms for nonacademic activities and social exposure. The EAHCA has institutionalized mainstreaming. ${ }^{78}$ For mild handicaps, the shift has been from self-contained class placements to a resource room model. Nonetheless, the extent of mainstreaming still is heavily dependent on attitudes of the staff and administrators. ${ }^{79}$ Indeed, available data and qualitative judgments indicate little overall impact on the extent to which handicapped children are mainstreamed.80

On the other hand, the slight impact may simply be the result of a limited objective. At least one commentator has observed that the mainstreaming concept was aimed largely at the practice of "dumping" handicapped children into inadequate special education programs. ${ }^{81}$ And, unlike placing children who are completely excluded from school, or writing IEP's where none existed before, mainstreaming is not so much a specific, concrete objective as a value, a "moral triumph." 82 More than any other aspect of special education law, mainstreaming is a subtle, subjective concept that cannot be easily measured.

b. The Contribution of EAHCA legalisms to the bottom line. Some of the chronologically sequenced procedures established by Congress correspond more or less directly to one of the objectives described above, while others are aimed at a broad spectrum of objectives. This section examines some of the key procedures and evaluates what is known about their role in realizing EAHCA objectives. While it is clear that the EAHCA is not the sole mechanism contributing to the progress of handicapped children in receiving special educational services, and thus cannot take either full credit or blame in that

without concessions to the IEP workload volume. By stressing that the IEP is not an instructional plan, but merely a set of benchmarks, the Department reinforces the view that it recognizes the need for streamlining the IEP process. It is not clear, however, that streamlining IEP terms helps better insure education agencies against adverse due process hearing results or whether it may ease the workload at the cost of a higher risk of loss in the event parents file complaints. Id. at 38 .

77. Although we know that IEP's are, by and large, not really individualized, we do not know how much individualization there is in practice. That is, students may be slotted into programs, nonetheless there may be a considerable amount of individualized instruction that occurs as a matter of course within the classroom. Further, comparatively speaking, children in special education may receive more individualized attention than they ordinarily would receive as students in regular classrooms.

78. SRI FinAL, supra note 49 , at 50-56.

79. Id. at 105-13.

80. Fifth Annual Report, supra note 51, at 15 (little change between 1977-78 and 1980-81 in percent of children mainstreamed); see also Turnbull, Brotherson, Czyzewski, Esquith, Otis, Summers, Van Reusen \& DePazza-Conway, A Policy Analysis of "Least Restrictive" Education of Handicapped Children, 14 Rutcers L.J. 489, 530-31 (1983) (qualitative assessment of least restrictive environment policy implementation indicates little movement toward greater adherence to policy as result of the EAHCA).

81. Note, Enforcing the Right to an "Appropriate" Education: The Education for All Handicapped Children Act of 1975, 92 HaRv. L. REV. 1103, 1121 (1979).

82. L. Lynn, supra note 37 , at 41-42. 
regard, it is the most important and the most heavily studied. ${ }^{83}$

(i) Child Find. Child Find has been the principal means of identifying handicapped children entirely excluded from public education. There are at least four reasons for its considerable success. First, field level advocacy groups monitored LEA and SEA Child Find efforts and actively assisted school officials in locating excluded children. ${ }^{84}$ Second, school officials have no discretion with regard to excluded children; they may not be excluded under any circumstances. Discretion arises only in regard to the nature of the services these children will receive. Third, although Child Find activities were initially burdensome, the burden was mediated by several factors. Child Find activities did not require LEA's to develop new programs or new recordkeeping procedures. LEA's normally conduct school censuses, run systematic screening programs, and notify their communities of important matters (such as immunization requirements) through the media. Child Find requirements fit within this administrative framework and therefore required little adjustment by the system. ${ }^{85}$ The fact that most LEA's easily systematized and implemented Child Find activities suggests a manageable administrative impact. $^{86}$ In addition, advocacy groups helped alleviate the need for LEA's to develop new avenues of community contact, thus compensating for whatever organizational weaknesses did exist. Fourth, LEA's usually receive special education funds from outside sources on the basis of the number of children they have identified as requiring special educational services. ${ }^{87}$ Therefore, LEA's generally have a financial incentive to find previously excluded children, even though they may not have a similar incentive to provide appropriate services ${ }^{88}$ The only real question is why the anticipated cost of special education services did not restrict the success of Child Find. Lack of discretion under the law and excellent local "enforcement resources" are probably adequate answers to this question. ${ }^{89}$

(ii) Referral mechanisms. The success of referral mechanisms designed to ensure that children already in the system are provided special education services appropriate to their handicapping condition ${ }^{90}$ is not as uniform or clear

83. See, e.g., SRI Final, supra note 49, at 133.56 (on major impact and central importance of the EAHCA to special education reform).

84. See, e.g., Kirp, Buss \& Kuriloff, supra note 46, at 71 (effective child find activities require advocacy group vigilance); Lazerson, supra note 59, at 38-39 (on importance generally of advocacy groups in getting attention for excluded children).

85. While school districts that responded poorly to Child Find requirements, such as Philadelphia, may simply have been intransigent in opposition to handicap rights, they may also simply have been bureaucratically inept and disorganized.

86. See, e.g., SRI FinAl, supra note 49, at 16-17; Kirp, Buss \& Kuriloff, supra note 46, at 61 .

87. The EAHCA allocates funds to states on the basis of the number of children each state counts as handicapped. 20 U.S.C. $\$ 1411$ (a) (1982).

88. For a discussion of the complex incentive structure created by the EAHCA, see M. ThомAs, supra note 48; Magnetti, supra note 39.

89. It may be that LEA's can exert discretionary powers successfully at later stages in the service process. See, e.g., In re Kanawha County School Dist., 3 [\$ 504 Rulings] Educ. Handicapped L. ReP. (CRR) 257:439 (Sept. 28, 1983) (children identified as handicapped were placed on a waiting list instead of being provided with special education services).

90. It is difficult to know how many children might fall into this group. Part of the problem is 
as the success of Child Find. Referral to a school's evaluation process begins each handicapped child's participation in special education programs. Regular classroom teachers are the principal source of special education referrals, ${ }^{91}$ although referrals come from a variety of other sources, including parents, health and special education professionals, and supplementary service teachers. ${ }^{92}$ Consequently, regular classroom teachers have potentially enormous discretion in determining whether children needing special education services will receive them, particularly because the EAHCA does not provide any specific guidelines for teacher referral practices.

Teachers exercise this discretion both to underrefer and overrefer children they suspect of having handicapping conditions. Sometimes teachers do not refer children whom they believe are handicapped. ${ }^{93}$ Underreferrals are the product of assessment backlogs, ${ }^{94}$ program availability, ${ }^{95}$ and nonuniform standards for handicap evaluation. ${ }^{96}$ While it is clear that more in-school

the lack of a solid baseline indicating the total number of handicapped children. Estimates made around 1970 of the number of children having handicapping conditions varied from 4 percent to 24 percent of the total youth population. G. BREWER \& J. KaKaliK, supra note 68, at 80 . Congress estimated in 1975 that one-half of this handicapped population, or something on the order of 4 million children, received inappropriate educational services. 20 U.S.C. $\$ 1400(b)(1)$, (3) (1982). But inasmuch as few children are now totally excluded from the schools and only about 4 million children receive special education services, it appears that the congressional estimate was excessive. A 1968 estimate indicated that 38 percent of all handicapped children were enrolled in special education programs. Lazerson, supra note 59, at 38 . Congress concluded that many children did not receive the service most appropriate for their individual needs. 20 U.S.C. $\S 1400(b)(2),(3)$ (1982). Of course, children may properly be referred, and yet receive inadequate services due to evaluation and placement decisions. See infra notes 112-13 and accompanying text.

91. See Bickel, Classifying Mentally Retarded Students: A Review of Placement Practices in Special Educalion, in Placing Children in Special Education: A Strategy for Equity 182, 187 (1982) (teachers are the most important source of referrals); Applied Management Sciences, supra note 58, at 5 (study of a 1980 representative sample of 100 school districts, including a random sample of over 400 schools and 7,000 school personnel, analyzing administrative records, self-administered questionnaire responses, and personal interviews, showed that regular education teachers referred 68 percent of the newly identified and placed handicapped students for the 1980-1981 school year).

92. Bickel, supra note 91, at 187; Applied Management Sciences, supra note 58, at 4.

93. Bickel, supra note 91 , at 188 (teachers withhold referrals because assessment backlogs frustrate their efforts to get special education services to children who need them). Of course, many teachers may not exercise their referral discretion at all in some cases because they do not feel they know enough to be sure that the child should be referred in the first place. See L. MCDonnell \& M. McLaughlin, Education Policy and the Role of the States 130-31 (1982) (in a study of a large urban school system, one-third of elementary and two-thirds of secondary teachers said they felt unprepared to identify handicapped children).

94. See C. Blaschke, Case Study of the Implementation of P.L. 94-142-State A: Final RePORT 57 (1979) (ERIC Doc. No. ED 175233) [hereinafter cited as C. Blaschke, State A]; C. Blaschke, Case Study of the Implementation of P.L. 94-142-State B: Final Report 44 (1979) (ERIC Doc. No. ED 175234) (three state case studies, each examining three school districts, revealed that teachers become frustrated because referred children often wait up to two years for assessment services) [hereinafter cited as C. Blaschie, State B].

95. See Weatherly \& Lipsky, Street Level Bureaucrats and Institutional Innovation: Implementing Special Education Reform, 47 HARv. Educ. Rev. 171, 187 (1977) (administrators in a studied school district told principals to curtail evaluations because placements are too costly; referrals in another district done on basis of program availability); SRI Final, supra note 49, at 48-49 (districts only recommend services they already can provide); Bickel, supra note 91 , at 188 (program availability can severely influence identification of handicapping conditions).

96. See Bickel, supra note 91, at 188-89 (a child's special education program may be determined by the referring teacher in some places, rather than by evaluation staff; ambiguity in program eligi- 
youth are underreferred than children who are excluded altogether, the precise number is uncertain. ${ }^{97}$

It is likely that underreferral stems from a child's personality traits. ${ }^{98}$ For example, children who are marginally in need of special education services, or children whose need, in the teacher's judgment, is too slight to warrant labeling the child or disrupting the child's class schedule, are commonly underreferred. ${ }^{99}$ The underreferral problem may be remedied through nonschool referrals, improved teacher training in special education, and increased resources to eliminate conditions which make teachers hesitant to make bona fide referrals; 100 however, underreferral is a boundary problem the extent of which will probably remain indeterminate and problematic due to the nature of any system which requires an eligibility cutoff. In a system of limited resources, teachers quite understandably will attempt to make adjustments to the system as a means of insuring that children with the most serious problems receive the first attention. ${ }^{101}$ Indeed, without that discretion to underrefer, teachers could seriously overload the system's ability to meet its legal mandate in other respects.

The more problematic use of teacher discretion lies in overreferral of children for evaluation. ${ }^{102}$ Some teachers discovered that they could use their referral power to rid themselves of troublesome and disruptive, if not handicapped, children. ${ }^{103}$ Early in EAHCA implementation, teachers could purposefully misrefer because assessments frequently were hastily conducted ${ }^{104}$ and because school districts frequently employed inappropriate assessment tools. ${ }^{105}$ However, as the referral and assessment process has stabilized and

bility criteria may create wide variation in referral decisions); Gov'T Accounting Office, supra note 46, at 43-46 (states set specific priorities for numbers of students to be served, for example, in secondary education, which causes variation in referrals).

97. The Government Accounting Office (GAO) observes that there is an uncertain number of children underreferred (that is, handicapped children in school but not receiving services), with the lowest estimate-derived from education agency service delivery claims-being perhaps as few as 100,000 children. The worst case estimate is that 2 million children are not receiving services. The GAO strongly questions this latter figure, but is unable to determine what a reasonable figure would be. Gov't Accounting Office, supra note 46, at 46.

98. See Applied Management Services, supra note 58, at 5 (only about one-half of 2.8 million students for whom regular education teachers requested special education were found eligible and were provided special education services).

99. See Bickel, supra note 91 , at 189 (children with emotional problems or who were quiet and well-behaved were likely to be underreferred).

100. Cumulative Effects, supra note 75, at 62 (teachers and special educators report ambivalence about usefulness of labeling in providing educational services).

101. Id. at 108 (assessment backlogs persist as a source of teacher frustration and still produce decisions not to refer because delays are so long that referral does not seem worth it).

102. The EAHCA mandates a triage system. See 20 U.S.C. $\$ 1412$ (3) (1982) (states must give first priority to handicapped children who are receiving no education at all, and second priority to the children with the most severe handicaps within each disability who are receiving an inadequate education).

103. Brown, supra note 46, at 22-24 (explaining how some teachers have used the special education system to rid themselves of difficult children).

104. Bickel, supra note 91 , at 194 (referral backlogs affect quality of assessments as school systems attempt to catch up on work load).

105. See id. at 196-97 (suggesting that, regardless of apparent assessment practices, education agencies frequently relied exclusively on IQ tests, despite directive of the EAHCA to do otherwise, 
assessment techniques have improved, teachers are finding it more difficult to "dump" children into special education. ${ }^{106}$ Special education personnel have used mandated assessment procedures (tests, M-teams, etc.) to prevent regular classroom teachers from dumping nonhandicapped children. ${ }^{107}$ Hence, the system has adjusted successfully to prevent the more gross and conscious special education misplacements.

Most referrals, however, are made in good faith, and good faith has led teachers to err on the side of caution, thus resulting in significant overreferral. The EAHCA did anticipate that it would be difficult for teachers accurately to assess which of their students were handicapped, and established inservice training requirements as a method of insuring the development of increasingly accurate referral. ${ }^{108}$ To date, however, inservice training largely has failed to provide the level of training which is needed to prevent mistaken referrals.

Although most special education teachers have received preservice training in assessment, ${ }^{109}$ regular classroom teachers have not received much assessment training, even at the inservice level. ${ }^{10}$ Much LEA-based inservice training has focused on formal compliance (special education procedures and orientation to special education laws), though some districts have offered more substantive training. ${ }^{11}$ Some problems are due to teacher resistance to additional inservice programs and the lack of programs which teachers consider useful, ${ }^{112}$ but the biggest obstacle to improved training is low budgetary priority. ${ }^{113}$ When LEA's are faced with the immediacies of evaluation and placement and the possibility of expensive court action from failing to follow the requirements of due process, inservice training receives a low priority because it has a distant and imprecise payoff and little direct relation to reducing risks or immediate staff workloads. Teacher layoffs may also be a problem, because they tend to eliminate teachers with the most preservice

thereby leading many education agencies to place children in inappropriate programs); P. KURILOFF, D. Kirp \& W. Buss, When Handicapped Children Go To Court: Assessing the Impact of the Legal Reform of Special Education in Pennsylvania 163 (1979) (National Institute of Educ. Project No. Neg.-003-0192) (school districts tend to equate retardation with performance on I.Q. tests); cf. SRI Final, supra note 49, at 33 (children are more likely to be better assessed now than in the past).

106. See, e.g., Cumulative Effects, supra note 75, at 96 (it is becoming more difficult to dump children who merely are difficult to handle); Applied Management Services, supra note 58, at 10 (suggesting that use of more complete range of assessment instruments has helped prevent teachers and diagnosticians from placing minority students as frequently in special education programs as their intuitive judgments indicate).

107. See Cumulative Effects, supra note 75, at 130 (special education teachers are making sure troublesome students are not being inappropriately "dumped" into special education programs).

108. See 20 U.S.C. $\$ \$ 1400(b)(7), 1413$ (a)(3) (1982); S. Rep. No. 168, 94th Cong., 1st Sess. 33 (1975), reprinted in 1975 U.S. CODE CONG. \& AD. News 1425, 1456-57.

109. Applied Management Sciences, supra note 58, at 6-7.

110. See SRI FINAL, supra note 49, at 61 (in-service training has not received much emphasis in school districts); L. McDonnell \& M. McLaughlin, supra note 93, at 128-30 (observing slow pace of inservice program development).

111. SRI Final, supra note 49 , at 62-63.

112. Id. at 64-66.

113. Id. at 65 . 
training. ${ }^{114}$

Many school districts have recognized that mistaken referral places an unnecessary burden on special education staff because complete and accurate assessments can be extremely time-consuming, and have responded by developing formal or informal prereferral screening procedures to produce more accurate referrals. ${ }^{115}$ These procedures are organizational innovations not required by the EAHCA. Prereferral activities vary from intervention documentation by classroom teachers to formal prescreening teams who consult with teachers regarding potential referrals. ${ }^{116}$ It appears that prereferral does ease evaluation backlogs. ${ }^{117}$

Since prereferral screening is not aimed at increasing the system's base of substantive special education knowledge, it may simply permit financial and other nonsubstantive considerations to be factored into placement judgments before the system is ever legally committed to notify parents of a decision to evaluate the child. On the whole, it is difficult to know which way prereferral screening cuts with respect to ensuring accuracy in special education placements.

(iii) Testing and evaluation. The EAHCA requires multiple-testing and bias-free test instruments to assure appropriate, individualized placement of children with special educational needs. As schools have accommodated themselves to the various demands of the law, they have increasingly used more neutral, balanced, and time-consuming testing approaches. 18 Indeed, on the average, diagnosticians now use about six assessment instruments for each child. ${ }^{119}$ It is thought that the quality of evaluations has improved over the years and that errors in the evaluation process are less likely now than during initial EAHCA implementation. ${ }^{120}$ Without necessarily creating any

114. The most recently trained teachers are the first to be laid off, and these teachers, whether in regular or special education, are more likely to have had the best preservice training in both substantive concerns and in EAHCA requirements.

115. SRI Final, supra note 49, at 17; A. Altman, J. Miller \& M. Brandis, Verification of Procedures to Serve Handicapped Children: Final Report-Assessment Component (1980) (ERIC Doc. No. ED 201 114). School districts have adopted these prereferral screening techniques in part because teachers do not have the needed special education identification skills. See U.S. DEPT. of Education, fourth annual Report to Congress on the implementation of Public Law 94142: The Education for All Handicapped Children ACt xiii-xiv (1982) (estimating that 25 percent of elementary teachers and 40 percent of secondary teachers have had training in identification of handicaps) [hereinafter cited as Fourth Annual Report]; $c f$. L. McDonnell \& M. McLaughlin, supra note 93, at 130 (survey of over 700 teachers in large metropolitan area revealed that 40 percent of elementary teachers and 57 percent of secondary teachers had had no training in implementing the EAHCA).

116. SRI FINAL, supra note 49 , at 18-19.

117. Id. at 21 ; Mehan, Identifying Handicapped Students, in Organizational Bemavior in Schools AND School Districts 391 (1981).

118. SRI Final, supra note 49 , at $32-33$.

119. Applied Management Sciences, supra note 58, at 9 . However, the use of a large number of assessment instruments still does not demonstrate that the IQ test or some other aspect of the referral and assessment process is not the single determinative factor in the final assessment disposition. See Bickel, supra note 91, at 196-97. Nonetheless, at least superficially, compliance with the letter of the law has improved.

120. SRI FINAL, supra note 49 , at 27-33. 
new placement opportunities, testing practices have, on the whole, contributed to assuring more appropriate, individualized placements in whatever programs are available. This improvement has occurred for several reasons. Administrators have lent support to the referral-assessment continuum because they have found it has contributed generally to their school systems' ability to identify and place children. ${ }^{121}$ The assessment legalisms have thus helped schools more ably perform their traditional sorting function. ${ }^{122}$ In many districts, the assessment procedure became less burdensome because districts increased special education funding. LEA's also have moved from an ad hoc approach to a more systematic compliance approach, which permits them to do assessments in less time.

Finally, the specialization of the work force has had a significant impact. Special education staff members now in the schools come out of college trained to deal with EAHCA requirements. They see as natural what older staff members considered novel and burdensome. The younger staff may also have a greater commitment to the handicapped than the older staff members and a greater commitment to the system because the EAHCA has given them an esteem and power that they did not have before Congress passed the law. ${ }^{123}$ In essence, they have a professional investment in a quality evaluation program.

On the other hand, the EAHCA's testing mechanism does not unequivocally contribute to a more appropriate, individualized assessment for the handicapped. For example, minorities are assessed with essentially the same techniques used for nonminorities; few school districts use culturally fair techniques.124 Hence, the 'Act's testing legalism may not be adequately addressing the problem of disproportionate minority placements.

In addition, overreliance on the IQ test, which has been thought to lead to many inappropriate placements, may not be eliminated by multiple testing. Multiple testing may simply "mask" continued use of the IQ test as the critical assessment tool. Other factors reducing our understanding of and confidence in the effect of multiple testing are the unreliability of test results (for example, IQ test results become less reliable as the results move further from the norm) and variations in the skill levels of the test givers. Conceivably, more accurate placements could come simply from multiple application of a single test, or a few comparable tests.

Local variations in testing and evaluation also tend to affect the positive impact of the procedure. For example, eligibility criteria vary enough that a given child could be classified as handicapped in some school district in the

121. See Cumulative Effects, supra note 75, at 65-66, 79.

122. See generally R. Callahan, Education and the Cult of Efficiency (1962); J. Spring, The Sorting Machine (1976); D. Tyack, The One Best System: A History of American Urban EducaTION (1974).

123. Cumulative EfFects, supra note 75 , at 116.

124. Cf. Applied Management Sciences, supra note 58, at 11 (minorities are assessed with test batteries virtually identical to those used with white children). 
state but as not handicapped in another district in the same state ${ }^{125}$ In addition, the EAHCA leaves the choice of testing instruments completely to the discretion of educators at the field level, thus creating variability through test choice. Assessment rates may also be affected by assessment styles favored by the evaluation staff. ${ }^{126}$ For example, evaluators inclined to take a behavioral approach to evaluation will follow the results of assessment instruments closely. On the other hand, professional staff who favor an informal intuitional approach are likely to make pro forma use of assessment instruments and distrust the results of those tests. ${ }^{127}$ Differences in diagnostic criteria have been a problem, but their current importance is unknown.

The costs of existing testing methods also must be considered since giving special educators so much discretion may be expensive and may detract from the day-to-day quality of the assessment process. For example, one urban LEA faced with vague eligibility criteria and shrinking resources had to spend a large amount of staff time in creating and revising its special learning disabilities guidelines. ${ }^{128}$ Special education assessments are time-consuming and generate a lot of paperwork. ${ }^{129}$ In the early stages of EAHCA implementation, evaluators often were overwhelmed by the number of referrals and serious evaluation backlogs occurred. ${ }^{130}$ Consequently, school districts initially responded to their increased evaluation workload by increasing evaluation staff, making less than thorough evaluations, and relying heavily on IQ tests for handicap evaluation purposes. ${ }^{131}$ Evaluation backlogs have been reduced by many districts, but some particularly large urban districts continue to be plagued by these backlogs. ${ }^{132}$ School districts are under pressure to

125. Id. at $70,92-95$.

126. Special education professionals have considerable problems in achieving diagnostic congruence. That is, given a particular child, professionals are likely to provide a variety of diagnoses for that child. Inconsistencies in these diagnoses may derive from the use of different diagnostic criteria, different theoretical frameworks, variance in the weighting of diagnostic data, incorporation of nondiagnostic biasing of the information, and changes in diagnostic style by a single professional within and across cases. Professionals also may make consistent errors in diagnosis which depend on nonverifiable diagnostic techniques or on the assumption that it is always the child, and not something else, which is the source of the child's problem. See, e.g., McDermott, Sources of Error in the Psychoeducational Diagnosis of Children, 19 J. SCH. Psychology 31 (1981).

127. Cumulative EfFects, supra note 75, at 105-08.

128. SRI FINAL, supra note 49 , at 32.

129. See, e.g., SRI FINAL, supra note 49, at 32-33 (evaluation process is time-consuming and generates much paper work); Cumulative EFfEcts, supra note 75, at 114 (counselors and special education teachers hit hard by administrative paperwork associated with EAHCA).

130. SRI Final, supra note 49, at 28; C. Blaschke, State B, supra note 94, at 44; C. BlaschKe, STATE A, supra note 94 at 56-57.

131. SRI Final, supra note 49 , at 25.

132. Parents must receive written notice whenever an education agency initiates the identification and preplacement evaluation of a child. 34 C.F.R. $\$ 300.504$ (a)(1) (1984). Parents who object to the identification or evaluation may initiate a due process hearing at any time after they have received the written notice. Id. $\$ 300.506$ (a) (1984). Education agencies must hold, within thirty calendar days, meetings with the parents of any child for whom a determination has been made that the child needs special education and related services. Id. $\S 300.343$ (c) (1984). The IEP developed out of this meeting must be "implemented as soon as possible" after the meeting. Id. $\$ 300.342(\mathrm{~b})(2)(1984)$. State laws paralleling the EAHCA may have similar or more stringent timelines. 
process referrals quickly ${ }^{133}$ because evaluation delays create due process compliance problems for school districts. ${ }^{134}$ Therefore, though the Act has encouraged complex, sensitive evaluation mechanisms, it frequently has failed to significantly change old practices precisely because the evaluation mechanism is complex and sensitive.

Finally, although assessments for handicapping conditions are objective in theory, in practice, the LEA's resources influence eligibility criteria and placement recommendations. ${ }^{135}$ A strong tendency exists for LEA's to assess a child only if the child's disability fits a preexisting special education program, or to find that the child's assessment happens to fit the child into an existing program. ${ }^{136}$ The most objective and accurate testing program cannot overcome inadequate resources. Unless the testing mechanism is given an independent financial role, it is unlikely to have the impact that the special education reformers hoped it would have. ${ }^{137}$

(iv) IEP's: substance. The basic question of whether the substance of IEP's leads to more appropriate educational placements logically entails two subordinate questions: whether the plans are any good (do they follow the content requirements of the Act?); and whether the plans are complied with or followed in practice. The literature reveals different answers to the two questions. Good paper compliance suggests that the IEP's are good but some

133. See infra note 185 and accompanying text. In most if not all federal courts, school districts will not become liable for damages for violation of the EAHCA unless it appears that they have seriously violated the Act's due process provisions. See, e.g., Anderson v. Thompson, 658 F.2d 1205 , 1214 (7th Cir. 1981). Therefore, school districts have an incentive to follow the formal procedures established by the Act in order to avoid financial liability for substantive evaluation errors.

134. Bickel, supra note 91, at 193-97; SRI Final, supra note 49, at 28-29. Of course, taking shortcuts may occasionally cause districts to alienate a parent whom a more careful procedure might have assuaged. Taking shortcuts therefore can also cause districts to end up in a due process hearing. But clearly the resource tradeoff, at least in the early stages of implementation when the process is largely ad hoc and unsystematized and the staff is on a relatively more inefficient point of its learning curve, favors shortcuts in required procedures. The risk is a potentially greater (but unlikely) expense in the event that the shortcutting leads to time-consuming compliance efforts by resource and staff stemming from an adverse result in an administrative hearing.

135. SRI Final, supra note 49, at 26, 48-49; Gov't Accounting OfFice, supra note 46, at 72-73.

136. Cumulative Effects, supra note 75, at 61-62, 92; Brown, supra note 46, at 32.

137. The interplay of resources and commitment is further demonstrated by the implementation of reassessment procedures for children already placed in special education programs. LEA's usually place little emphasis on reassessment, even though it is a kind of safety net for a child who is erroneously placed and whose parents fail to object to the placement. SRI FinaL, supra note 49 , at 27; Cumulative Effects, supra note 75, at 105-06. The LEA's give reassessment attention equal to that of initial assessment only when SEA monitoring or court cases push them to do so. SRI FINAL, supra note 49, at 27; Designs for CHANGE, supra note 53, at 2. (Of course reassessment may not be of much use if it is done hastily, without reforms in referral practices, and without adequate testing instruments.) Resources are not the only problem, however. For example, school psychologists traditionally have not been involved in reassessment functions, and because they are the ones usually burdened with reassessment duties, they have given reassessment a low priority. Without external pressures, they responded to the demands of the EAHCA by conforming to the traditional school psychologist function. P. Kuriloff, D. KirP \& W. Buss, supra note 105, at 92-107. Court actions sometimes have led to significant changes in testing because they compelled shifts in financial resources. See, e.g., Larry P. v. Riles, 495 F. Supp 926 (N.D. Cal. 1979); United States v. Board of Educ., 80 F.R.D. 679 (N.D. Ill. 1980) (consent decree). 
evidence shows a loose correspondence between the IEP's and actual programs. How did the pattern of formal compliance develop?

IEP provisions initially imposed a significant burden on LEA's. ${ }^{138}$ Although most education agencies created IEP's for children who needed special education services, ${ }^{139}$ these initial IEP's frequently omitted EAHCA-mandated information and often contained useless provisions. ${ }^{140}$ As time went on, rather than shedding the IEP, education agencies brought the plans into a high degree of compliance with the Act without a corresponding change in actual educational programs. This differential evolution might be explained as a classic pattern of formal compliance, or goal displacement, in which more strenuous compliance efforts are directed toward the activity monitored by regulatory inspectors than toward the activity with substantive significance. A second appealing explanation is the loose coupling literature as explicated by the sociologist John Meyer. The "institutional" aspects of schools, such as grades, diplomas, and IEP plans are relatively easy to conform to environmental demands, as compared with the "technical" aspects, like what actually goes on in classrooms. An IEP plan could say all sorts of good things about how classroom teachers should help a particular child. Changing the behavior of classroom teachers, who are bombarded by conflicting demands in a fluid, shifting environment, is not so easy. The plans may or may not be doing some good, as a "model" to be emulated, for example. But in the best of all possible worlds, goals will be easier to manage than actual behavior. ${ }^{141}$

There are several reasons to believe that the classic pattern is operative in this case. First, well-formulated IEP's serve the local education agency as documentation of procedural compliance in the event a child's parent or guardian files a formal complaint and the education agency ends up in an administrative or judicial proceeding. ${ }^{142}$ IEP's are the essential audit track for litigation. Second, many state education agencies monitor IEP's only for paper compliance and do not apply effective sanctions for noncompliance. Only about one-third of state education agencies examine IEP documents for their substantive correctness during site visits to local education agencies. Even these

138. SRI FINAL, supra note 49 , at 34

139. A National. Survey Of IEPs: Vol. I, supra note 73, at 4 (approximately 95 percent of the children identified as requiring special education had IEP's on file); SRI FINAL, supra note 49 , at 34 (most children in 1978-79 in districts studied had IEP's); Cumulative EfFEcTs, supra note 75, at 105 (initial IEP's generated in most instances).

140. A National Survey of IEPs: Vol. I, supra note 73, at 7, 11 (only 40 percent of the IEP's were "informative and internally consistent"; only 5 percent of the IEP's were judged "exceptionally informative and internally consistent").

141. On paper compliance, see SRI FINAL, supra note 49, at 34-49 (IEP's are routine practice and more technically complete, while their substantive use is declining); A National Surver of IEPs: Vol. I, supra note 73, at 13 (IEP's have become more internally consistent). On goal avoidance, see infra note 194 and accompanying text. For John Meyer's work, see infra note 218 . On the different constraints which operate on goals as an ideological system versus actual behavior, see Etzioni, supra note 5 .

142. See Proposals to Amend Pub. L. 94-142, 1981-82 Educ. HandiCapped L. ReP. (CRR) AC125, 126 (Supp. 71, April 30, 1982) (criticism of proposed amendments to the EAHCA on grounds that they would eliminate documentation which school boards need in establishing the appropriateness of their educational plan in the face of a parental challenge). 
relatively few diligent states usually restrict themselves to inspection of the plans. California may be alone in attempting to use independent classroom observations to determine whether the actual instructional programs conform to each child's IEP. ${ }^{143}$ Even when the states have seriously monitored LEA's and discovered problems, they usually have not applied permissible legal sanctions. Instead, states have chosen less coercive and more informal means of obtaining compliance. ${ }^{144}$

Third, paper compliance was easier than expected. Educators are complaining less about the IEP burden because it literally has become less burdensome; they have not shed IEP's because they can live with them. Some studies suggest that burden is primarily subjective and that, after educators accepted the legitimacy of the Act and understood the purpose behind the paperwork, the burden did not seem so great. ${ }^{145}$ After the initial shock, the unreasonable tends to become routine.

Finally, local education agencies continue to develop IEP's because the IEP process has had a positive impact on schools as a whole. The IEP procedures have led LEA's generally to develop better staff program planning skills, better diagnostic and evaluation techniques for all students, and better training programs for teachers. ${ }^{146}$ Indeed, one study indicated that each studied district stated that it would retain the IEP process in some form even if the EAHCA were abolished. ${ }^{147}$. The administratively burdensome IEP process also turned out to be a positive educational innovation. Programs may not correspond closely to plans, but the educational effects are positive anyway (e.g., better placement into whatever programs are available). Thus, the paper compliance is not really only paper compliance, although the substantive changes were not the ones anticipated by the legislation. (The interesting phenomenon of unanticipated positive consequences also occurs in connection with due process and is characteristic of the substantive educational innovations developed by educators in response to "legalization"-the

143. Cf. Fourth AnNual Report, supra note 115, at 65-68. The lax monitoring data come from an unpublished 1981 survey of nineteen states conducted by the National Association of State Directors of Special Education (NASDSE Study). The monitoring process varies significantly among and within states. Several states apparently believe they have no legal authority for their monitoring function. There is some indication that state monitoring is gradually becoming more rigorous with respect to substantive aspects of IEP's. But the federal Office of Special Education Programs found in 1980-81 that "none of the 21 states visited were effectively identifying and determining all actual or potential problems in educating handicapped children in accordance with PL 94-142," and that the states were not taking effective steps to remedy the deficiencies they did find.

144. Id. at 66-68. Frequently, states offer education agencies technical assistance if they are having problems complying with EAHCA requirements.

145. Cumulative EfFEcts, supra note 75, at 113; SRI Final, supra note 49, at 45.

146. Cumulative Effects, supra note 75, at 79; SRI Final, supra note 49 , at $46-47$.

147. Fourth Annual Report, supra note 115, at 28. Eighteen of the twenty local education agencies in an unpublished study conducted in 1981 by the National Association of State Directors of Special Education (NASDSE) strongly supported the IEP process. Sixteen agencies said they would retain the IEP conference and fifteen said they would document IEP's just as they did presently even if federal and state mandates were discontinued. All local education agencies said they would use the IEP in some form even if the federal and state requirements were abolished. It is possible, however, that a strong bias exists in the result of this study because of the small sample and the perspective of the group performing the study. 
substantively empty proceduralisms typical of the EAHCA. Both are discussed below.)

(v) IEP's: parental participation. Congress enacted the IEP requirement as a means of ensuring that education agencies would provide all handicapped children with an appropriate education. At one level, the law required SEA's to monitor IEP's largely by verifying paperwork. The state role, however, is after the fact. Congress believed that immediate parental input in IEP conferences was a crucial means of catching potentially erroneous placements which had escaped detection in the referral and evaluation stages.

Initially, the IEP did increase parental participation in creating programs for their handicapped children, although the degree of participation varied from school district to school district. ${ }^{148}$ However, the initial upsurge in parental participation quickly leveled. ${ }^{149}$ The typical pattern now is that significant numbers of parents do not appear at all for IEP conferences, while those who do attend do not provide significant input. ${ }^{150}$ There appear to be two reasons for this rather low rate of active participation.

First, quite frequently the school district's evaluation and placement recommendations do not propose so significant a change that parents are willing to object. ${ }^{151}$ Therefore, while significant numbers of parents may not be

148. See SRI FINAL, supra note 49, at $39-40$ (noting initial upsurge and variability of participation); C. Blaschke, Case Study of the Implementation of PL 94-142: Executive Summary 20 (1979) (ERIC Doc. No. ED 175 232) (summarizing study of nine local education agencies in three states between 1977 and 1979; noting no dramatic increase in parent participation in placement decisionmaking).

149. SRI Final, supra note 49 , at 39-40.

150. One recent study of parents attending IEP meetings in a western school district indicates both the problems that parents have in using the IEP to their advantage and the problems in gauging exactly how well parents understand what is going on in the IEP process. In that survey, most parents-three-quarters-felt actively involved in the IEP process. When they were asked for specifics, however, parents included listening, understanding, and working with staff as active involvement; only 15 percent indicated that they ever expressed any opinion or made suggestions regarding the plan itself. Most parents claimed they understood the educational objectives, rights, and the IEP procedures; however, the survey did not make any objective determination of parent knowledge, so it is impossible to know if parents in fact understood sufficiently to participate. Their understanding is particularly cast in doubt because the survey data indicate that large percentages of parents had procedural and qualitative grounds for challenging the school's conduct. For instance, 5 percent of the parents did not receive an IEP to sign, 22 percent were not contacted prior to their child's assessment, 19 percent claimed the schools did not try to set a convenient meeting time, and 31 percent of the parents felt that their child was not receiving the appropriate training. Lynch \& Stein, Perspectives on Parent Participation in Special Education, 3 Exceptional Educ. Q. 56, 60 (1981).

A broader national study of IEP procedures indicated that parents only participate in creating the IEP about two-thirds of the time (though about three-quarters indicated that they had discussed IEP's with school personnel) and only one-half of the parents claimed that they provided "input" to IEP committees during the development of the IEP. Again, despite relatively large numbers of parents who did not participate in the IEP process at all or only marginally (only about one-half of the nationwide survey of IEP's indicated that the parents had even signed the document), less than 1 percent of the parents in the survey had refused to approve their child's IEP. See A National SuRvey OF IEPs: Vol. I, supra note 73, at 8-9. Perhaps the principal point to be made is that very little systematic knowledge exists regarding the nature of parent participation in the IEP process. See, e.g., Morgan, Parent Participation in the IEP Process: Does It Enhance Appropriate Education?, 3 ExcEPTIONAL EDuc. Q. 33, 34 (1982).

151. For example, one study comparing a small set of parents of learning disabled (LD) children-a frequently rather mild, if variable, form of handicapping condition-with parents of regular 
entirely happy with their child's IEP, 152 the program the school proposes may not raise parents' concerns enough for them to ask the school district to modify its proposal. ${ }^{153}$

Second, parents have a low rate of participation in conferences because the structure of parent-professional relations, ${ }^{154}$ the context of IEP confer-

education children found little difference between the groups in terms of parent involvement with their children's education. McKinney \& Hocutt, Public School Involvement of Parents of Learming-Disabled Children and Average Achievers, 3 Exceptional Educ. Q. 64, 68 (1981). Another study observed that parents were much more likely to participate in the IEP if the education agency recommended that the child be decertified. Parents became concerned that their child would be entirely cut off from needed services. See SRI Final, supra note 49, at 40.

152. There are no national studies which purport to question directly parents' satisfaction with their child's IEP. A study which surveyed four and one-half counties in the northwest corner of Iowa in 1979 found, on the basis of a 39.4 percent questionnaire response rate, that 3 percent of the families in that predominantly upper middle class area were dissatisfied with their child's special education program. See Polifka, Compliance with Public Law 94-142 and Consumer Satisfaction, 48 ExCEPTIONAL ChiLdren 250 (1981). Another study, conducted under the sponsorship of the California State Department of Education, took a random sample of 400 parents from a school district in Southern California which enrolled over 11,000 children in special education programs. Of those 400,328 were directly interviewed. The interviewers found that 31 percent of the parents to whom the question was applicable ( 71 of 229 ) felt that their child was not receiving appropriate life planning skills training. See Lynch \& Stein, supra note 150, at 56.

153. With procedural violations a commonplace, many more parents probably could get satisfaction from the due process proceedings than those who actually have complained about their child's placement. Undoubtedly for many parents the complaint does not seem worth the trouble. See supra note 151. On the other hand, many parents may not know they have a right to complain. See Lynch \& Stein, supra note 150, at 60 (15 percent not informed of rights); Polifka, supra note 152, at 252 (13 percent not informed of rights). The studies do not indicate if parents who tend to disagree with the placements are more likely not to know of their hearing rights than those who do agree with the placements. It may be that, in many circumstances, parents become motivated to challenge IEP's not so much because they are unhappy with the substantive program, but because they dislike the label the education agency attaches to it. Although in many instances educational activities for learning disabled (LD), mentally retarded (MR) and emotionally disturbed (ED) are nearly identical, parents frequently resist the idea that their child is retarded. Cf. FourTh ANNUAL RePort, supra note 115, at 106, 108-09 (between 1976-77 and 1980-81, the number of children classified as LD increased from 797,214 to $1,468,014$; the number classified as ED rose from 283,072 to 348,954 ; while those classified as MR dropped from 969,597 to 844,180 ).

Studies of the issues raised at due process hearings also suggest that labels are often the principal sore point, though this conclusion also varies a great deal. Compare Kirst \& Bertken, Due Process Hearings in Special Education: Some Early Findings from California, in Special Education Policies: Their History, Implementation and FinanCe 136, 143 (1983) (study of hearings in California during 1978-79 shows only a few-less than 3 percent-of the hearings revolved around classification issues) with P. Kuriloff, D. Kirp \& W. Buss, supra note 105, at 160-62 (of the 168 due process hearings in Pennsylvania held between 1975 and 1979, 64 involved parental resistance to a school proposal to classify their child as retarded or to remove the child from mainstream school activities; parents favored LD and normal classifications, while schools favored educable mentally retarded (EMR) classifications). For a classic labeling disagreement, see Anderson v. Thompson, 658 F.2d 1205, 1207 (7th Cir. 1981) (school district, after identifying child with exceptional educational needs in speech and language and further undifferentiated exceptional educational needs, recommended placement in an EMR classroom, while parents' independent evaluation found speech, language, LD, and ED problems; hearing examiner found no LD, EMR, or ED problem, but determined that speech and language disability existed, and approved moving child from a private school program to the school district's EMR classroom "because it offered all of the components necessary for the development of a program meeting [the child's] individual needs.").

154. See generally S. Lightfoot, Worlds Apart: Relationships Between Families and School 20-42 (1978) (discussing the tensions in parent-teacher relations); D. LORTIE, SCHOolteacher: A Sociological Study (1975) (discussing need of teachers to control degree of parent input); $M$. Miles, Common Properties of Schools in Context: The Backdrop for Knowledge Utilization and "School Improvement" 82-84 (1980) (Center for Policy Research, New York, N.Y.) (professionalism 
ences in the EAHCA regulatory scheme, and the structure of the IEP conferences themselves weigh against parent participation. Despite education professionals' long history of neglecting handicapped children and misusing special education services, ${ }^{155}$ parents nonetheless "tend to trust the placement and services recommended by the schools." 156 This residual trust comes in part from parents' traditional willingness to defer to professional educational judgment, ${ }^{157}$ reinforced by many educators' studied resistance to any parental input. ${ }^{158}$ Professional resistance may explain why IEP conferences frequently are highly formal, noninteractive, and replete with educational jargon. ${ }^{159}$ Professional resistance to parental input may also explain why one limited study found that IEP's were "always developed after the placement decision was made. . . "160 In a word, most educators are unac-

and the structure of the school bureaucracy buffer teachers and administrators from parental efforts to have input in school decisionmaking processes).

155. See, e.g., Lazerson, supra note 59.

156. SRI Final, supra note 49 , at 41.

157. See id.; Note, supra note 81 , at $1110-11$.

158. See Gilliam \& Coleman, Who Influences IEP Committee Decisions?, 47 Exceptional Children 642 (1981) (parents not perceived as equal partners); Goldstein, Strickland, Turnbull \& Curry, $A n$ Observational Analysis of the IEP Conference, 46 ExCEPTIONAL Children 278 (1980) (same); Yoshida, Fenton, Kaufman \& Maxwell, Parental Involvement in the Special Education Pupil Planning Process: The School's Perspective, 44 Exceptional Children 531 (1978) (most professionals do not think parents should be directly involved in planning special education); CumUlative EFFEcts, supra note 75, at 143 (educators disturbed by parental veto of program proposals not so much because of potential financial burden on school system but because parents are permitted to question successfully educators' professional judgment). Some school principals so resist any parent participation that many parents never even have an IEP conference. See C. Blaschre, State A, supra note 94, at 53-55 (in 1977, one district studied so entirely excluded parents that the Office of Civil Rights had to intervene). School principals seem less likely now to exclude completely parents from the IEP process than they did before the EAHCA, but significant proportions of parents may continue to be excluded altogether. For an example of professional educator resistance to lay input in England, see S. ToмLinson, A Sociology of SPECial Education (1982).

159. See Kirp, Buss \& Kuriloff, supra note 46, at 105-06 (pre-EAHCA study observed that educators break down parent resistance to program with overload of child's test results); SRI Final, supra note 49, at 22 (IEP conferences generally formal, not interactive); R. WEATHERLY, REFORMING SPEcial Education: Policy Implementation from State Level to Street Level 52-55 (1979) (conferences filled with "jargon"). At least one study has observed, however, that educators may just as well use "informal" or "interpretive" conferences as a method for successfully excluding parents from placement decisionmaking. S. Thouvenelle, J. Rader \& L. Mader, Study of Procedures for Determining the Least Restrictive Environment (LRE) Placement of Handicapped Children: Final Project Report 7.3 (1980) (ERIC Doc. No. 199981) (study of 134 placement meetings in 15 school districts located in 5 states) [hereinafter referred to as Study of Procedures].

160. Study of Procedures, supra note 159, at 7.5. Of course, some parents may find this summary treatment insulting enough to prompt them to push the education agency into a hearing. One study of Massachusetts parents who pursued administrative remedies after unsatisfactory IEP conferences explained the parents' reactions to education agency behavior at IEP conferences. One parent called the conference a "kangaroo court." Another said that, "At the end of it, they handed me a blank piece of paper and said, 'Sign.' There wasn't anything on the paper. It was just a blank form. So I said, 'I would like to go home and discuss it with my husband.' And they became very angry and said I would be preventing the child from getting what he needed. They try and make the parents guilty for not signing a blank piece of paper." M. Budoff, A. Orenstein \& C. Kervick, Due Process in Special Education: On Going to a Hearing 59 (1982) (longitudinal study of 80 families who participated in Massachusetts due process hearings between 1975 and 1977). Less blunt tactics left one parent feeling that " $[\mathrm{T}]$ hey listened, but they didn't listen, if you know what I mean. They listened, but they had their minds made up. The meeting is just really a pretense of listening, and then they write the plan they want." Id. at 61 . In this respect, education agencies that try so hard to 
customed to permitting parents an equal voice in educational decisions, and they have adapted the IEP conference legalism to perpetuate this customary relationship.

Beyond the structure of parent-professional relations, realistic organizational constraints made it necessary for LEA's to restrict parental participation. The first priority for school districts after passage of the Act was to identify and place previously neglected children. Since this requirement usually overburdened agency personnel, each step in the placement process had to be conducted as quickly as possible. Quick IEP meetings were expedient. ${ }^{161}$ Although hurried IEP meetings may simply have been, as noted above, another method intentionally applied to thwart parental input, in many instances educators simply were reacting to time pressures. ${ }^{162}$ The pressure to meet evaluation deadlines, the burden of handling due process hearings, and the large amount of paperwork and time commitments generated by the IEP process itself all motivated LEA's to rush IEP conferences and discourage parental participation. Parental participation was not bureaucratically efficient.

Finally, the structure of the IEP conferences themselves discourages parental participation. Parents are almost always outnumbered at IEP conferences. ${ }^{163}$ The dynamic of small groups usually prevents a minority viewpoint from exerting any real influence, even if the placement decision is not, as it usually is, predetermined. ${ }^{164}$ In fact, one study indicated that, even if parents assert themselves at IEP conferences, they implicitly follow the agenda set by the educators around the table. According to this study, educators do not raise the touchy issues, such as placement options, potential social stigma, or possible harmful effects of proposed placements. ${ }^{165}$ Further, as educators rarely organize their evaluation findings in a manner designed to create a coherent whole for the parent, parents find it difficult to reconstruct these

defuse parental input that they unilaterally end communication between themselves and parents may end up facing the very problem they sought to avoid. It might also be that these high-handed school tactics have been motivated by the belief that the IEP, which is supposed to be signed by the education agency and parents, is a contract to which the school could be bound. If the IEP were viewed as a contract, the education agencies would naturally have wanted parents to sign a blank piece of paper, since undoubtedly the financial burdens of special education frequently put school districts in the position where they do not feel they can afford to negotiate. The legislative history makes it clear, however, that the IEP is not a contract. See 121 Conc. REc. 19,492 (1975) (statement by Senator Williams, a principal sponsor of the EAHCA that the IEP conference does not create a "contractual relationship"). Inasmuch as only about one-half of the IEPs have parental signatures, it is apparent that many school districts do not strictly view the IEP as a type of contract. See A National SURVEY OF IEPS: VOL. I, supra note 73 , at 8.

161. C. Blaschke, State B, supra note 94, at 44; R. Weatherly, supra note 159 , at 87.

162. See R. Weatherly, supra note 159, at 56 (school officials were often willing and able to provide inquiring parents with useful explanations of what was going on, but school officials rarely volunteered those explanations because it took much longer to convey them).

163. For example, in the NASDSE study, described supra note 143, 11 of the 20 districts sampled indicated a median of 6 participants, with a range of 5 to 8 , for a mildly handicapped eighth grader. Fourteen of the 20 districts indicated a median of 6 participants, with a range of 5 to 10 , for a severely handicapped elementary school student. Fourth ANnUAL RePORT, supra note 115, at 29.

164. M. Budoff, A. Orenstein \& C. Kervick, supra note 160, at 62.

165. Study of Procedures, supra note 159, at 7.7-7.9. 
findings in the form of an alternative proposal. ${ }^{166}$

In sum, the IEP provisions of the EAHCA have increased parental participation somewhat, but probably not nearly to the extent that Congress originally contemplated. In the end, the IEP legalism seems ill-suited to significantly alter preexisting patterns of parent-school relations. ${ }^{167}$ If the IEP process has improved the rate at which children are appropriately placed in special education programs, it apparently does so not because of the specific contours of the process, or even because of the content of the IEP itself, but simply because some kind of process exists.

(vi) Due process. At the end of the chronological line of procedural mechanisms stands the EAHCA due process requirement, an administrative hearing designed to further none of the Act's objectives specifically and all of them generally. Because the requirement is designed in part as a deterrent whose effect is detectable only if parents insist on compliance, the role due process plays in the decisionmaking framework is difficult, if not impossible, to evaluate in situations when the process is not pursued ultimately to a hearing. ${ }^{168}$ However, the effectiveness of due process as a deterrent may be assessed in part by analyzing the cases where due process is used to see how frequently it is used, who "succeeds" in using it, how difficult it is to use, and whether it triggers the development of extra-legal mechanisms for solving the problems it was intended to solve.

Parents appear to win, and thus obtain desirable services and placements for their children, in slightly more than one-third of EAHCA hearings; 169 however, they must first get to a hearing. Few parents, as observed earlier, participate effectively enough in the IEP process even to raise a complaint. ${ }^{170}$ Even if parents have the skill and knowledge to raise complaints at the IEP

166. Id. at 7.6-7.9. One innovative school district-Madison, Wisconsin-has recognized the inevitable temptations and dynamic consequences of the IEP conferences format, and actively encourages parents to bring an advocate with them to an IEP conference. See J. Handler, The Discretionary Decision (1984) (unpublished manuscript).

167. See generally H. Broudy, The Real World of the Public Schools 20-38 (1972) (explaining why schools are unresponsive to externally initiated change); $M$. Miles, supra note 154 , at 73-96 (on mechanisms used by school systems to deflect and defuse forces attempting to compel change in the schools).

168. See generally Hawkins \& Thomas, The Enforcement Process in Regulatory Bureaucracies, in ENForcing REGUlation 3 (1984) (effectiveness of statute like the EAHCA significantly affected by enforcement practices from the top level of the hierarchy to the field level, and effectiveness is influenced by the complexity of the enforcement environment); Scholz, Cooperation, Deterrence, and the Ecology of Regulatory Enforcement, 18 L. \& Soc'y REv. 179 (1984) (describing the difficulty in predicting how deterrent structures will work in an organizational framework).

169. D. Kirp \& D. Jensen, What Does Due Process Do? ParC v. Commonwealth of PennSYlvania Reconsidered 15 (1983) (ERIC Doc. No. ED 229 878) (parents not likely to succeed on appeal); P. Kuriloff, D. KirP \& W. Buss, supra note 105, at 168 (parents won 35 percent of 168 hearings in Pennsylvania from 1974-78); Kirst \& Bertken, supra note 153, at 136, $139-45$ (study of 145 due process hearings in California held in 1978-79 indicates that parents achieved at least partial grants of their claims in 49 percent of the local decisions and state appeals); Smith, Status of Due Process Hearings, 48 Exceprional Children 232 (1981) (741 of 2,006 hearings won by parents in 38 states sampled up to 1980). A cautionary note: all of these data are quite old. It is not clear that parents have been as successful in recent years.

170. See supra note 150. 
conference, they may not have enough to succeed at a hearing. ${ }^{171}$ The relative handful of parents who do make it to a hearing ${ }^{172}$ must increasingly face the education agencies' winning documentation and procedural compliance strategy. ${ }^{173}$ Thus, a relentless attrition quells threats to the professional decisions of educators.

Even favorable results frequently have been of little comfort to parents. Some education agencies complied with the hearing officer's directives immediately; others waited until a few adverse decisions accumulated. On the other hand, there were many opportunities for procedural gamesmanship and noncompliance. Even if schools lost at the hearing level, they might appeal to the state level for relief from the hearing officer's decision. ${ }^{174}$ If the appeal process was not too discouraging, schools could still frustrate the parents by resubmitting the same plan that they originally gave to the parents, ${ }^{175}$ or by simply refusing to comply. In many instances, nothing compelled schools to provide the program the hearing system required. ${ }^{176}$ If these devices were too crude, districts also learned that they could temporarily comply, but then reevaluate the child at the legally mandated point (three years after the initial evaluation) and resubmit that original plan on the basis of their reevaluation. ${ }^{177}$

Of course, if hearing results sorted themselves out in a triage-like process based on the substantive worthiness of the claims and a precedent-based system, then the high rates of attrition would not be so troublesome. The due process system still would be systematically providing an appropriate education for all similarly situated children in an order corresponding to the severity of their needs. Due process could encourage all meritorious claims, however, only if it functioned informally enough that it would be easily, inexpensively, and equally accessible to each potential complainant.

171. M. Budoff, A. Orenstein \& C. Kervick, supra note 160, at 117-18 (discussing extremely extensive preparation parents must undergo before the hearings); cf. P. KuRILOFF, D. KIRP \& W. Buss, supra note 105, at 210-12 (parent success at hearings is strongly related to the depth of their preparation).

172. In 1979-80, only 0.065 percent of all children receiving special education services challenged any aspect of their special education program, while only 0.007 percent actually filed a complaint in any court. Children's Defense Fund, Comments of the Children's Defense Fund on the Department of Education's Proposed Regulations Implementing Pub. L. 94-142, at 5 (Dec 3, 1982) (formal comments).

173. P. Kuriloff, D. Kirp \& W. Buss, supra note 105, at 205-06 (school districts tend to do better in hearings if they show they have complied with procedural requirements of law); L. McDonNELL \& M. MCLAughlin, supra note 93, at 124 (state education agencies emphasize correct EAHCA procedures in their monitoring of local education agencies, rather than insure that there is an appropriate match between the child's diagnosis and the educational services the child receives).

174. See M. Budoff, A. Orenstein \& C. Kervick, supra note 160, at 144 (in a study of Massachusetts hearings, several parents gave up because they could not afford to appeal, or simply did not want to continue in the process); P. KuRILoff, D. KIRP \& W. Buss, supra note 105, at 238-39 (noting that administrative appeals process in Pennsylvania between 1972 and 1975 distinctly favored school districts).

175. M. Budoff, A. Orenstein \& C. Kervick, supra note 160 , at 139.

176. Id. at 121-22, 141, 149; $c f$. Fourth Annual Report, supra note 115, at 65-68 (on gentle enforcement monitoring practices of state education agencies).

177. M. Budoff, A. Orenstein \& C. Kervick, supra note 160, at 142. 
Instead, the due process system increasingly has moved away from such informality. The financial cost of hearings may be substantial for both sides, although these costs may vary considerably depending on factors such as the extent of legal assistance the parties employ. ${ }^{178}$ The high costs associated with these procedures probably skew hearings toward the more financially consequential handicaps, since parents who have much to gain from a favorable decision presumably will be more willing to accept high litigation costs. Even more important, far from being unintimidating, the hearings process exerts a terrible toll on the participants. Parents, teachers, and administrators all become very frustrated by the process because it demands so much of their time, because it challenges their personal and professional integrity, and because it represents an utter breakdown in communication. ${ }^{179}$ Breakdowns in communication may be so severe that the substantive issues between the parties cannot be resolved until either the family or the school administrator moves out of the school district. ${ }^{180}$ Not surprisingly, the hearings have become less like informal dispute resolution and have taken on characteristics of judicial procedures. ${ }^{181}$

At the same time that effectively limited access to the system has cut into the range of substantive complaints addressed by the due process procedures, the hearing system has failed to generate the necessary precedential value. ${ }^{182}$ Each due process hearing depends on an ad hoc analysis that, at least formally, ignores past solutions to similar problems.

Despite the apparent failure of the due process procedures to address the imbalance of power between individual parents and education agencies, there

178. See M. Budoff, A. Orenstein \& C. Kervick, supra note 160, at 113-14, 139 (describing wide variation in hearings cost for parents, ranging from a few hundred to thousands of dollars); State of Minnesota Department of Education, The Impact of Conciliation Conferences and Due Process Hearings, 1981-1982 (1983) (some parents' hearing costs in the hundreds of dollars range; hearings costs for school districts in the several thousands of dollars range) [hereinafter cited as Minnesota Mediation]; Fourth Annual Report, supra note 115, at 46 (average hearings may cost state education agencies thousands of dollars); Bickel, supra note 91, at 211 (attorney fees and time necessary to follow due process hearings for both parents and schools may depress use of hearing process); Kirst \& Bertken, supra note 153, at 141-42 (noting hearing costs for school districts ranging from several hundred to a few thousand dollars).

179. See M. Budoff, A. Orenstein \& C. Kervick, supra note 160, at 56-63, 69-72, 77-83, 101-18, 127-30, 203-04, 208-11 (poor parent-school communication and very heavy workloads take toll on parents and educators in terms of energy, morale, sense of integrity, and professional competence).

180. Id. at 210 .

181. See id. at 202, 324-26; D. Kirp \& D. Jensen, supra note 169, at 30; Fourth AnNual RePort, supra note 115 , at $47-48$.

182. See M. Budoff, A. Orenstein \& C. Kervick, supra note 160, at 125, 195-96 (hearing officers' actions, by not precisely specifying the educational program, often lead to a further hearing aimed at clarifying the original hearing decision; school administrators tend to see hearing process as substantively unpredictable); $i d$. at 333 (unique case facts prevent precedents from being established); D. KIRP \& D. JENSEN, supra note 169, at 20-30 (hearing appeals decisions permit divergent diagnosis of the handicap of a given child to withstand review, and restrict authority of hearing officers to solve educational problems); id. at 15 (noting that the use of individualized education may so affect hearing process that hearing officers may refuse to follow precedent because each case is too individualized); P. KuRILOFF, D. KIRP \& W. Buss, supra note 105 (noting that hearings officers in Pennsylvania frequently were prevented or discouraged from making specific substantive placement recommendations). 
nonetheless are indications that due process gives parents leverage against education agencies. The unpleasant qualities of due process hearings have led a number of states to develop prehearing mediation procedures. These mediations are not part of the special education law; at least one state (Pennsylvania) has run into difficulties with the Department of Education because the federal authorities felt that the mediation process was used by the state to circumvent the hearings process. ${ }^{183}$ It is clear, however, that the mediation process is significantly supplanting the need for due process hearings in several states. ${ }^{184}$ For example, in 1981-82, only five of Minnesota's eighty-four conciliation cases ended up at a formal hearing. ${ }^{185}$ In 1981, sixty-four of Connecticut's eighty-three mediations reached agreement. Only twelve of the remaining cases resulted in a hearing. ${ }^{186}$ Thus, perhaps because it better preserves the long term cooperative relationship between parents and schools, ${ }^{187}$ mediation may be a more effective mechanism than the due process hearing for ensuring that more children receive an appropriate, individualized education in the least restrictive environment. Mediation, rather than the due process hearing, seems to achieve the informality which encourages meritorious claims.

In sum, the due process hearing probably has increased the proportion of handicapped children receiving an appropriate education, though the magnitude of the increase is unknown. While we suspect that due process has had a small impact on the delivery of special education services, ${ }^{188}$ that impact undoubtedly varies significantly among states and among districts within states. As in the case of every other part of the procedure, variables outside the system, such as the presence of active parent groups, financial status of the education agency, and administrative style of the local educators, are critical determinants of procedural effectiveness.

183. D. KIRP \& D. JENSEN, supra note 169 , at 16 . Minnesota had to arrange a special agreement with the Department of Education to keep its mediation process. See Minnesota Mediation, supra note 178 , at 10 .

184. See Fourth ANNUAL RePort, supra note 115, at 47-48.

185. Minnesota Mediation, supra note 178 , at 4 .

186. Division of Elementary and Secondary Education, Connecticut State Department of Education ANalysis of 1981 Special Education Mediations 1 (1982).

187. See Macaulay, Non-Contractual Relations in Business: A Preliminary Study, 28 AM. Soc. Rev. 5567 (1963).

188. Perhaps one reason for the failure of due process requirements to have a larger impact on the delivery of special education services is that the courts have, by and large, not pushed hard to create a remedial framework which will weigh rather heavily on the minds of educators. One reason for this, of course, is that it is difficult, if not impossible, to decide whether the parents or educators will have the better substantive arguments because the state of knowledge is often rather primitive. See, e.g., Board of Educ. v. Rowley, 458 U.S. 176 (1982) (Court concluded that it cannot determine who has the better substantive position). In any case, courts have been unwilling to provide remedies which have enough bite to be influential at the field level of decisionmaking. Few courts will give damages, attorney fees, or compensatory educational service remedies under the EAHCA. For policy arguments against broad-stroke damage remedies, see Hyatt, Litigating the Rights of Handicapped Children to an Appropriate Education: Procedures and Remedies, 29 U.C.L.A. L. REv. 1 (1981). For a general analysis which suggests why the structure of school-parent relationships embodied in the EAHCA precludes much better results for due process, see J. Handler, supra note 166. See generally Galanter, Why the "Haves" Come Out Ahead: Speculations on the Limits of Legal Change, 9 L. \& Soc'y REV. 95 (1975). 
B. What Causes the Implementation Gap? Political Adjustments and the Limits of Legalization

After comparing reformist objectives with implementation realities and briefly exploring organizational/political reasons for the difference, it is time to focus more sharply on the organizational/political explanations. We need to collect and collate the various kinds of interpretations we have already made and transpose them into a more systematic framework.

The gap between reformist objectives and implementation is often explained in passive terms, like inertia or complexity. Explanation is sometimes avoided by referring to unexpected consequences. In contrast, a political explanation presupposes political activity. Gaps occur because the priorities represented by the law enter a world with many other priorities. What is sometimes referred to as a unilateral process of enforcement and impact actually is an interactive process of mutual adjustment. Legal objectives are compromised so that other objectives do not need to be compromised, or compromised so much. One person's gap is another person's gain. ${ }^{189}$

This section of the article attempts to demonstrate the essentially political character of EAHCA implementation more systematically than the densely factual narrative of the preceding section. To show the interactive nature of the process, the law is represented as a set of initiatives or resources, which the active environment of law answers with initiatives and resources of its own.

1. Law as Resources and Limitations on Those Resources. Why does a law such as the EAHCA cause any social change at all? Why is it not simply ignored? Literally speaking, enactment of legislation consists of putting words on paper. How and why do those words change behavior?

One way to answer these questions is to conceive of law as a set of initiatives and resources. To a certain extent, law itself acts as an initiative because of the general law-abiding nature of people. A complex law like the EAHCA probably does not create much automatic compliance, however. For such a law, compliance occurs because people are encouraged or allowed to request or demand compliance from regulated organizations. A law like the EAHCA is a "demand entitlement," a resource for those inclined to ask for change.

Those requesting change include state and local education agencies, either undertaking a process of voluntary compliance or seeking information about legal requirements from federal agencies and service organizations. Federal agencies engage in both formal and informal enforcement and assistance.

189. This description is especially appropriate for what has been called the "compliance relationship" (as opposed to the "deterrence relationship"). In the compliance relationship, both parties have a high degree of social legitimacy and the emphasis is on preventing rather than punishing harms. See Clune, supra note 2, at 65-66; Hawkins \& Thomas, The Enforcement Process in Regulatory Bureaucracies, in Enforcing Regulation 3, 8-9 (1984); Reis, Selecting Strategies of Social Control Over Organizational Life, in ENForcing Regulation 23 (1984). 
Outside the government, advocacy groups, individual advocates, and individual parents make demands on schools, request hearings, complain to enforcement agencies, and bring court actions. All of these people use four basic kinds of resources: new financial resources (federal aid); a new source of moral authority (the idea that handicapped children have a right to more educational resources); the substantive right provided by the law (an appropriate education, as defined by regulations and courts); and, most important in the case of the EAHCA, the right to demand a whole set of new organizational procedures (child finds, referrals, new tests, M-team assessments, IEP's, due process hearings).

Change is limited because the resources used by these groups and individuals are limited. Federal aid was limited, especially as initial commitments were compromised under fiscal pressure. The EAHCA's direct service requirements were a relatively efficient means of requiring that money be spent for the purpose intended. ${ }^{190}$ Even so, the availability of financial aid for intended beneficiaries is always problematic. ${ }^{191}$ New moral authority is offset by countervailing moral authority (e.g., the claim of resources, such as teacher and psychologist time, for the handicapped versus other uses). ${ }^{192}$ The substantive right to an appropriate education was vague. Although it suggested some content, its essential definition was procedural; appropriate education became the education defined by key decisionmakers during implementation. Enforcement agencies, hearing officers, school officials, and courts determined the meaning of appropriate education, and all were more or less responsive to competing claims for resources. Practically speaking, implementation is a process of compromise, in which legal scholars as well as courts take part. Several of the articles in this volume, for example, contain carefully developed doctrinal methods for balancing the needs of the handicapped against other claims. ${ }^{193}$

Limitations on procedure as a resource are especially significant because of the importance of procedure under the legislation. Two kinds of procedures established by the Act should be distinguished for analytical purposes: the organizational routines, such as IEP's, required of all schools for all chil-

190. For a discussion of the direct service requirements of the EAHCA compared with other types of grant mechanisms, see Barro, Federal Education Goals and Policy Instruments: An Assessment of the "Strings" Attached to Categorical Grants in Education, in The Federal InTERest In Financing Schooling 229 (M. Timpane ed. 1978).

191. The basic problem with financial aid is additivity-aid recipients reduce their own expenditures on the aided activity and save the difference or spend it on something else. See Barro, supra note 190; Clune, Serrano \& Robinson: Studies in the Implementation of Fiscal Equity and Effective Education in State Public Law Litigation, in Schools and Courts 67-120 (P. Piele ed. 1979). See also supra note 39 and accompanying text.

192. See supra note 189 and accompanying text.

193. See, e.g., Bartlett, The Role of Cost in Educational Decisionmaking for the Handicapped Child, LAw \& Contemp. Probs., Spring 1985, at 7; Wegner, Variations on a Theme-The Concept of Equal Educational Opportunity and Programming Decisions Under the Education for All Handicapped Children Act of 1975, LAw \& Contemp. Probs., Winter 1985, at 169 . On the lack of substance and procedural quality of the EAHCA, see supra note 36; Buss, Special Education in England and Wales, LAw \& Contemp. Probs., Winter 1985, at 119; Yudof, Education for the Handicapped: Rowley in Perspective, 92 AM. J. EnuC. 163 (1984). 
dren; and litigation entitlements, which establish the right to complain on the part of enforcement agencies and parents. Organizational routines are subject to the problem of formal compliance. ${ }^{194}$ Organizations lacking a clear substantive direction or strong commitment to the protected group can reach any preferred result following proper procedures. M-teams using broadly based tests can produce properly drafted IEP's to justify almost anything short of complete exclusion. The effectiveness of the procedures depends upon the skill and motivation of various people involved, but the degree of skill and the commitment of school personnel toward the handicapped varies greatly. Model communities may exist side by side with communities that lag far behind in implementing the Act. ${ }^{195}$ Among those motivated to use the new procedures constructively, formal compliance presents a different problem. Resources used to meet formal requirements detract from actions that are more efficient in particular contexts. ${ }^{196}$

Litigation entitlements are subject to similar limitations. Federal and state enforcement agencies have limited resources and other responsibilities. Political pressures and divided loyalties may prevent the use of available enforcement resources. Enforcement also tends to gravitate toward formal compliance. Formal compliance is more easily monitored than substantive compliance (especially when the substantive right is vague and invites compromise), but formal compliance also is tempting politically. In choosing a high standard of procedural compliance coupled with a low standard of substantive compliance, and a high degree of deference to professional decisionmakers, ${ }^{197}$ courts have adopted a relatively nonintrusive, nonactivist role.

The plasticity of substantive rights, organizational routines, and administrative enforcement partially explains the relative ineffectiveness of parental entitlements. If parents had a clear entitlement (for example, a right to $\$ 500$ upon determination of a handicapping condition), backed up by a strict enforcement agency, things might be different. ${ }^{198}$ Of course, all litigation entitlements (complaint-triggered liability systems) ${ }^{199}$ are constrained by the cost of litigation, both financial and personal, and by the many advantages to

194. In formal compliance, rules are followed technically, but the underlying purpose of the rule is frustrated. Such means/end conflict has been called "goal avoidance." See E. BARDACH, supra note 8, at 85-95; P. Blau, The Dynamics of Bureaucracy-A Study of Interpersonal Relations in Two Government Agencies 231-65 (2d ed. 1963); J. Pressman \& A. Wildavsky, Implementation I passim (2d ed. 1979); P. Selznick, Law, Society, and Industrial Justice 13 (1969); P. Selznick, TVA and the Grass Roots-A Study in the Sociology of Formal Organization 259 (1949) ("deflection of goals"); Barro, supra note 190, at 229.

195. Paul Berman emphasizes the importance of matching implementation strategies to the type of regulated enterprise and situation. See P. Berman, From Compliance to Learning: ImpleMENTING Legally-Induced Reform 27-28 (1981) (Institute for Research on Educational Finance and Governance, Stanford University, Project Report No. 81-A20).

196. The idea that field-level inspectors and regulated enterprises can often find a more efficient way to meet regulatory goals than the way specified in the law is at the heart of E. BARDACH \& $R$. KAGAN, supra note 8, at 99-104.

197. Board of Educ. v. Rowley, 458 U.S. 176 (1982).

198. See Rebell, Educational Voucher Reform: Empirical Insights from the Experience of New York's Schools for the Handicapped, 14 URB. LAw. 441 (1982).

199. See Clune \& Lindquist, supra note 7 , at 1083-88. 
institutional repeat players. ${ }^{200}$ Parents' effectiveness in the school setting is further reduced by their special relationship with schools-not simply a continuing relationship based upon trust but a highly dependent one as well. ${ }^{201}$ Professor Handler aptly identifies the class of problems as dependent relationships and discretionary decisions. ${ }^{202}$

\section{Reprise: Strengths and Weaknesses of Legalization as a Source of Social Change.} A process of political adjustment during implementation takes place regardless of the type of legal intervention. Policy instruments very unlike the EAHCA evoke similar processes of adjustment (vouchers, categorical grants, teacher training, mental health and employment programs, and the Tennessee Valley Authority (TVA), for example). ${ }^{203}$ One way to sharpen the discussion of the limits of change under the EAHCA is to focus on the specific policy instrument used in that law and many others.

Choosing a word for this kind of policy instrument is not easy because of the typical problem of terminology in the social sciences; a variety of words with overlapping but also inconsistent meanings are used to describe approximately the same things. The word adopted in this article is "legalization." "Legalism" was an earlier choice, ${ }^{204}$ but that term may have pejorative connotations. A term permitting both positive and negative elements is preferable. Legalization also has serious disadvantages. Professor Kirp restricts the term to judicial interventions establishing individual rights and relying heavily on due process. ${ }^{205}$

Our usage is much broader. Legalization is most usefully defined broadly and functionally as a mechanism of social control (or influence) characterized by externally observable routinized behavior. ${ }^{206}$ The essence of legalization, whether ordered by a legislature, court, or administrative agency, is the requirement of standardized organizational behavior (routines) designed to be observed, audited, and monitored from other social locations (e.g., enforcement agencies). ${ }^{207}$ So defined, legalization reaches into every area of organizational life, including categorical financial aid (involving monitoring of the use of money), planning (e.g., programmed budgeting, school improvement plans), client influence (e.g., due process rights), and routine administration (e.g., audits, record keeping, reports).

200. See Galanter, supra note 188 (advantages of "repeat players").

201. In this respect, the difficulties in using legal remedies in the school situation are greater than those in the continuing business relationships described by Macaulay, supra note 187 .

202. J. Handler, supra note 166.

203. See, e.g., supra notes 191 \& 194.

204. Clune, Rationalistic and Political Interpretations of Legalism: A Review Essay on Bardach \& Kagan's Going By The Book (unpublished paper presented at the annual meeting of the Law \& Society Association, June 1983).

205. See Kirp, supra note 9.

206. This was how "legalism" was defined in Clune, supra note 204

207. The "monitorability" aspect of legalization is sometimes the source of efficiency (when individualized decisions are too expensive), sometimes the source of inefficiency (when only individualized decisions will do), and sometimes the source of political oppression (when monitoring is done for the sake of domination or disruption). See Clune, supra note 204. 
Formally, that is, ignoring important patterns of informal influence and communication, ${ }^{208}$ the EAHCA is entirely composed of legalizations. Various procedures are imposed to implement accurate referral, assessment, and placement, such as Child Find census operations, multiple-testing instruments, interdisciplinary evaluation teams, and IEP's. Parental influence is routinized by veto power over evaluation ${ }^{209}$ and placement, participation in the IEP conference, and due process rights or litigation entitlements which compel school authorities to go through certain legal routines on parental demand. Financial aid, in the manner typical of federal programs, is targeted on districts with high concentrations of the protected class of children. ${ }^{210}$

Such a functional definition makes it easy to see the strengths and weaknesses of legalization as a source of social change. Widespread change can be produced quickly for two different reasons. As a matter of bureaucratic enforcement, organizational routines are easily monitored and relatively easily adopted. Second, the availability of substantive rights and litigation entitlements instantly authorizes a potentially large class of well-motivated private enforcers, especially when, as in the case of special education, private complainants are numerous, well-informed, and organized at the grassroots.

The weaknesses of legalization as a method of social change are the three great weaknesses of proceduralism: resistance, lack of substance, and cost.

a. Resistance. The formal goals of legalization represent the aspirations of the group seeking compensation through legal reform (or, more narrowly, social movement activists), and do not take account of opposing interests whose preexisting priorities must be altered in order to provide compensation. That is, formal goals represent ideals without resistance. ${ }^{211}$ Procedures and new organizational routines are enacted for the benefit of the protected class, but they are equally available to other interests even though such interests usually benefit from advantages outside the statutory framework. Apart from the relationship between the parties, schools have several important

208. Legalization requirements are just words on paper until someone decides to do something with them. From the enforcement side, "using" legalisms may consist of actual use, as in lawsuits, threats of use, and informal sanctions, such as paperwork. See M. Feeley, The Process Is the Punishment: Handling Cases in a lower Criminal Court (1979); P. Hill, Enforcement and Informal Pressure in the Management of Federal Categorical Programs in Education 14-29 (1979) (Rand Note No. N-1232-HEW). Beyond all of these, however, enforcement agencies often try to assist regulated organizations with compliance through such devices as consultation and professionalization of staff. See P. Berman, supra note 195; M. Derthick, The Influence of Federal Grants 158-218 (1970).

209. 34 C.F.R. $\$ 300.504$ (c)(2)(i) (1984) (public agency may use hearing procedures to override parental veto of evaluation or initial provision of special education and related services).

210. See Magnetti, Some Potential Incentives of Special Education Funding Practices, in Placing CHILdren in Special Education: A Strategy for Equity 300, 315-16 (1982). The EAHCA funding formula is located in 20 U.S.C. $\$ 1411$ (1982).

211. This is the great irony of the Reagan Administration attack on affirmative action. Such things as goals and timetables start out compromised (by such things as good faith exceptions), see Clune, supra note 2, at 59-60, and are further compromised in practice. Thus the "rigidity" of affirmative action is purely rhetorical, absolute demands being necessary as a bargaining chip, see infra part III; and the attacks against it, if successful, will destroy or cripple a program that is already discounted just short of the point of being completely ineffective. 
advantages in the adversary process, such as money, time, expertise, and social power. The special relationship between parties which is characteristic of regulatory law increases that advantage. Regulation usually takes the form of the "compliance relationship,", 212 a somewhat contradictory relationship in which the regulated institution is distrusted to the extent that voluntary compliance is considered unlikely, yet trusted at least in the sense that fundamental social legitimacy and continued existence is presumed. This trust may extend even to a sense that a continuing mutually satisfactory relationship is the object of the distrust-motivated system of regulation. All such procedures thus have a difficult dual mission: encouraging complaints against the system, and creating a cooperative relationship between system and challenger. Very often the indispensable quality of the cooperative relationship negates the realistic possibility of challenge-or limits challenging to special cases as, for example, in the case of relatively wealthy parents seeking very large financial benefits from private placements.

b. Lack of substance. Lack of educational substance is the next great weakness of a legalistic solution. Legalization is a crude device sometimes useful as a means of obtaining resources but hardly ever useful in suggesting educational solutions. An organizational routine such as the IEP can capture the attention of an organization, but it cannot provide a good education. Bureaucratic rigidity and technical ignorance remain untouched by due process. Budgeting implications of the right to an appropriate education were left vague, to be hammered out in various procedural forums. Organizational planning and staffing were also underemphasized. The result of all this is a rather strange, but in some ways admirable, process in which the educational content of rights is developed improvisationally in response to sporadic pressure. Schools must develop new programs, personnel skills, and organizational routines in order to meet all demands impinging on the system. Special education cannot have an infinite budget either in dollars or in educational programs. In the best case, schools must "fit" a group of programs with what seems to be the overall mix of demands and needs. In the worst case, schools are frozen in resistance or technical incompetence, subjected to the aimless pressure of legalization or to no pressure at all.

Thus, a system of proceduralization like the EAHCA creates a substantive underground of educational practice consisting of educational solutions created in response to the law but nowhere specified in it. Advocates, schools, researchers, and government agencies cooperate in devising new solutions. ${ }^{213}$ But the solutions bear the mark of improvisation. They are erratic and incom-

212. See supra note 189.

213. On the EAHCA as both a civil rights statute and education initiative, see Yudof, supra note 193. Examples of efficient, humanizing, organizational innovations in special education are: having other children in the class help push wheelchairs, and finding out which teachers do not really mind or can easily adapt to catherization. See generally Kimbrough \& Hill, The Aggregate Effects of Federal Education Programs (Sept. 1981) (Rand Working Paper No. R-2638-Ed.). 
plete because the law provided for demands, rather than responses to demands.

c. Cost. Cost is the last weakness of legalization. Organizational routines are expensive, especially when they require the participation of specially trained personnel. Because of the pressure of enforcement, formal compliance automatically becomes a high priority even if it is substantively unproductive. ${ }^{214}$ Even more important is the stress and confusion produced by the substantively empty procedural solution. Schools are told to do something under penalty of the law, but they are not told what to do or how to do it. Meeting the demands of each parent is not sufficient. There must be some overall organizational planning and development.

3. Summary. Seasoned observers of legalization are rarely pleased by it. ${ }^{215}$ Much happens quickly, partly because of a lot of wasted motion. Benefits are widespread, but they are also uneven and unpredictable. Resources are mobilized, but the educational practice needed to use those resources is left hanging, improvised by school people confused and agitated by an urgent yet strangely uninformative law. ${ }^{216}$ Given this ambivalence, whether to like or dislike legalization is partly a function of perspective and expectations. ${ }^{217}$ Anti-legalists become preoccupied with costs and the formal, symbolic character of compliance. ${ }^{218}$ As a general matter, we are on the pro-legalistic side of neutrality because of what seems to be a potentially dangerous bias in the

214. See supra note 194 .

215. See supra note 9; D. KirP \& D. Jensen supra note 169; D. KirP \& D. Jung, Schools AND Rules: Understanding Legalization in Comparative Perspective (1983) (Institute for Research on Educational Finance and Governance, Stanford, Project Report No. 83-B5); Kirp, Professionalization as a Policy Choice: British Special Education in Comparative Perspective, 34 WorLd PoL. 137 (1982); Neal \& Kirp, supra note 36. Ambivalence in a situation of considerable benefits and considerable costs is understandable. Professor Kirp's work on legalization may suffer from a certain unwillingness to strike a final balance.

216. Much research on the effect of educational resources, whether dollars, teacher qualifications, learning and teaching time, library books, etc., fails to show any strong educational effects, because the research failed to investigate how resources were transformed at the school level into educational outputs. R. BARr \& R. Dreeben, How Schools Work 1-4 (1983); H. Levin, About Time for Educational Reform (Aug. 1983) (Institute for Research on Educational Finance and Governance, Stanford University Project Report No. 83-A 19); MacKenzie, Educational Productivity and School Effectiveness 30-35 (1983) (unpublished manuscript) (Research Synthesis and Policy Analysis, Southwest Educational Development Laboratory, NIE Contract No. 400-83-0007).

217. For example, one's perceptions of whether the costs of legalization are worthwhile is extraordinarily sensitive to one's evaluation of the substantive right in question. See Clune, supra note 2, at 90 ; Clune, supra note 7 , at 765 n. 12 .

218. Anti-legalism (the idea that regulation does not produce much useful behavior change) comes from rather different directions: a rationalizing, cost-conscious impulse, e.g., E. BARDACH \& R. KaGan, supra note 8; a radical, unmasking impulse, e.g., J. Edelman, Political Language: Words That Succeed and Policies That Fail (1977); and a symbol-concious sociological impulse, e.g., Meyer, Strategies for Further Research: Varieties of Environmental Variation, in ENVIRONMENTS AND ORGANIZATION 352, 355-57 (1978); Meyer \& Rowan, Institutionalized Organizations: Formal Structure as Myth and Ceremony, 83 Ам. J. Soc. 340, 346-48 (1977); Meyer \& Rowan, The Structure of Educational Organizations in Environments and Organization 78, $79-81$ (1978); Meyer, Scott, Cole \& Intili, Instructional Dissensus and Institutional Consensus in Schools, in Environments and Organization 233, 256-63; J. Meyer, W. Scott \& T. Deal, Institutional and Technical Sources of Organizational Structure Explaining the Structure of Educational Organizations (May 1980) (unpublished manuscript on file with the author). 
anti-legalist position. The ultimate advantage of legalization is the production of rapid change through substantively empty demand entitlements. The thin, formal quality of these entitlements can produce a serious underestimation of their value in the minds of those demanding an unrealistic degree of intellectual coherence in social life. The empty entitlements can work surprisingly well as the structure for legally unspecified but practically effective social action. In organizations with a high degree of cooperation and skill, the legal rules may provide a stable structure within which to conduct preferred interactions. In highly resistant organizations, the entitlements eventually may provide the key which unlocks the door for progressive change. All sorts of social action benefitting children flows both around and through established procedures. For example, parents may not participate effectively in the IEP conference, but they might have had a useful conversation with school personnel in anticipation of the conference.

In one sense, the value of legalization in the abstract is much too general a question to be useful. Legalization works better or worse across a wide range depending on context. Precisely how well this disorderly and unpredictable process of change turned out in special education is the subject of the next part of the article. As will be seen, because of the characteristic grass roots social activism of parents and special education advocates, special education is a very good-perhaps the best-case for legalization. Other factors, such as the dependent relationship between school and parent, cut in the opposite direction. Before getting to such pragmatic issues, however, a difficult normative question about the proper standards of evaluation must be unravelled.

\section{III}

The Special Education Gap Evaluated: What Should Be Done Now?

Preceding sections have described the special education implementation gap and explained how political adjustments between various interested parties are responsible for it. This part of the article is concerned with evaluation. Does the gap indicate failure? What can and should be done to narrow it?

Three aspects of evaluation are problematic and require discussion: the problem of standards (by what measure is success evaluated?); the overall evaluative assessment (given some standard, how can the success of the law be summarized in some meaningful way?); and the related issue of reform (what is worth trying to change?).

A. The Problem of Standards: Success for Whom, and How Much is Enough

Difficulties in measuring the effects of law are serious enough without additional complications, but the problem of choosing standards for evaluation is almost as difficult. Different people and groups evaluate government 
policy from different perspectives. ${ }^{219}$ An abject failure from one perspective may be a satisfactory result from another, and divergent perspectives may use similar or completely different criteria.

Three basic perspectives seem to compete for priority in most discussions. First, there is the purely political perspective, which looks to the real attitudes of political participants and certainly includes what are sometimes referred to as "latent" purposes, or "motivations," instead of legislative intent. 220 Real political standards include the goals of reformers but also include those of legislators who pass legislation as a payoff for campaign contributions or to prevent an electoral threat, such as the opposition of special education advocacy groups. Interests opposing the reform are important parts of the real political perspective, whether the opposition is on account of financial and/or personal cost or principle (lack of sympathy for the protected class). Welfare interests are real political purposes, especially the ever-present rationale of creating jobs through government programs.

Reformist goals are a special class of the real political goals, normally those identified as legislative purpose or intent. When advocacy groups or moral entrepreneurs sponsor legislation, the legislation as a whole probably will be justified in terms of some underlying need, and each major policy instrument contained in the legislation (e.g., financial aid, due process) likewise will have some formal justification. As compared with the full range of political goals, reformist goals are formal (highly rationalized), moralistic, and technical (the work of lawyers, policy analysts, legislative staff, and other experts). Notwithstanding this narrow point of view, evaluation is commonly measured against reformist goals. ${ }^{221}$ Due process is "supposed to" create parental participation rather than jobs for hearing officers although the latter is also a real political goal.

The third common evaluative perspective lies somewhere between the first two: the reformist perspective as modified by worthy competing considerations, often called "costs." Worthy competing considerations may be revealed by the legislative process, by public commentary, or during the process of implementation as, for instance, in arguments before courts. Many people who would not be willing to admit the propriety of all real political purposes would insist on counterbalancing reformist objectives with costs of reform. Thus, in our terms, the garden variety "cost-benefit" analysis of government policy probably represents a balancing of reformist objectives against socially legitimate competing considerations. (The omission of socially improper real political purposes from the benefits side of the equation

219. See supra note 217.

220. See Ely, Legislative and Administrative Motivation in Constitutional Law, 79 YALE L.J. 1205 (1970).

221. Sunstein, Public Values, Private Interests, And The Equal Protection Clause, 1982 Sup. CT. Rev. 127. Sunstein is correct that statutory interpretation (whether as part of judicial review or not) necessarily and properly involves a search for genuine and good public (collective) purposes. The specific suggestion of the article that pure redistribution should be the only unacceptable public purpose under the equal protection clause requires an extended response not appropriate here. 
is probably one reason why government policy is so frequently considered a failure.)

The "political method" recommended in this article is a version of the third alternative-reformist objectives as modified or discounted by socially important competing considerations. Each of the alternatives has arguments in its favor, however, and it is important to understand what is gained and lost by each possible choice.

Evaluating programs according to real political purposes has the advantage of social realism. Any subset of real political goals, such as reformist goals, has a problem of justification. For any operating social program, the political process has already registered and weighed the complete set of competing goals. By what authority can reformers, policymakers, and policy experts relitigate the same program giving stronger priority to a subset of the goals? The answer to this important and difficult question is not like preferred values and higher moral principles in constitutional law. ${ }^{222}$ However, while it is easy enough to disparage empty moralism, the alternative of cynical political realism seems equally unattractive. The most serious problem with real political evaluation is the "sociological fallacy," a brand of ethical postivism according to which everything that happens is not only good but equally good. Even in this disenchanted age, no amount of cynicism will convince anyone that all social programs are equally good. In a fundamental sense, evaluation is impossible without reformist standards. Evaluation implies the possibility of counterfactual conclusions. How is it possible to escape this radical swing from empty idealism to sterile realism, from opinion to fact?

Whatever the answer may be at the level of the individual, the social answer is relatively easy: democracy itself. ${ }^{223}$ Instead of contradicting democracy, reform-oriented (counterfactual) evaluation hopes to begin a new cycle of democratic action. Evaluation is not above politics; evaluation is politics. And, notwithstanding a prior political equilibrium, all sorts of reasons exist why reformist evaluation can be politically effective. At the social level, many people in the political process may be honestly ignorant or confused about what is going on. Some of the patterns revealed by implementation studies may be harmful to just about everyone and thus amenable to a statesmanlike remedy. Also, part of the preexisting political equilibrium may have required secrecy to be effective. "Latent" political purposes, such as pork barrel and symbolic politics, are not less real than manifest purposes, but they may be a great deal more difficult to defend in a public forum. The reformist purposes of law tend to be publicly acceptable and legally authorized purposes. If research shows that these purposes are not satisfied, the public may well demand an accounting through courts, legislatures, or administrative agencies. Of course, nothing guarantees the success of reformist research. The

222. In a liberal democracy, the preferred value of one group may be regarded by another group as simply a strong preference. See Komesar, Taking Institutions Seriously: Introduction to a Strategy for Constitutional Analysis, 51 U. CHI. L. REv. 366 (1984).

223. Clune, supra note 2, at 91-93. 
old political equilibrium may be unperturbed. The point here is philosophical and political coherence rather than political power. Reformist evaluation makes political and ethical sense, even if it gets nowhere.

Because of its counterfactual potential, reformist evaluation has been a mainstay of the sociology of law in the form of the paradigmatic gap study. ${ }^{224}$ The word "gap" faithfully describes the entire genre of research because the finding of gap studies is always that laws fail to achieve their reformist purposes-there is always a gap between reformist goals and real implementation. Under a political model of implementation, a gap is also to be expected, because implementation is conceived of as a long process of adjustment between reformist goals and competing interests. If, as just argued, reformist goals supply the requisite counterfactual component of evaluation, a gap study must be a part of every evaluation. An abbreviated gap study of the EAHCA is found in section II A of this article. The problem is what to conclude from the existence of a gap.

Gap studies usually conclude that government programs were failures. This uniform negative finding established the sociology of law as a force to be reckoned with; but, in the end, more questions were raised than answered. Theoretically and pragmatically, the idea of uniform, invariable programmatic failure seems implausible. Normatively and politically, the gap was catastrophic. Proposed initially by left-center social reformers as a justification for intensified government effort, the apparent inevitability of the gap eventually fostered the current mood of fatalistic neo-conservatism.

The problem with gap analysis is an incomplete normative argument-the gap in gap analysis. Evaluating empirical reality against reformist goals is a useful first step, but there are two other normative questions: a qualitative question about which goals other than reformist goals should be recognized, and a quantitative question about how much success is enough. A shortfall or deficit in reformist goals that occurs as a necessary result of promoting other socially worthwhile goals may be acceptable. On the quantitative side, the question is how much reformist success is enough to justify the intervention. Thus, gap analysis suffers from an idealogical fallacy, which is the antithesis of its counterpart discussed earlier, the sociological fallacy. While the sociological fallacy, which is the product of purely political evaluation, assumes the normative superiority of actual behavior, the ideological fallacy, which is an intrinsic part of gap analysis, assumes the primacy of reformist goals.

In ethically modified gap analysis, a question arises immediately about which nonreformist goals should be recognized. In theory, almost anything could qualify. Practically, the interests which compete for recognition are those revealed during implementation. (Some who receive benefits or bear costs may not be involved in implementation, or may not be well represented. This is a problem beyond the scope of this article.) Interests revealed during implementation have a pragmatic validity of the case or controversy variety.

224. See supra note 4. 
Those interests also have presumptive legal significance. ${ }^{225}$ In many social programs-and certainly in the EAHCA-much of the process of adjusting reformist goals against competing considerations had been delegated or deferred to the stage of implementation with all its various participants (including courts). ${ }^{226}$ Thus the normative significance of the adjustments is a question unexplored at the time of legislative enactment or judicial decree. Just as a judicial decision applying a statute or constitution is influenced by the concrete facts before the court, so the adjustments of implementation are influenced by newly acquired knowledge about specific program implications. 227 Perhaps a competing consideration was not given sufficient weight (the disruptions of mainstreaming?). Perhaps there were unforseen budgetary implications (the impossibility of complete individualization of instruction and complete remediation?). Perhaps some of the reformist ideals were not as important as others, or, in the light of pragmatics, seem patently unrealistic (parental power?).

The use of the term "a political method of evaluation" in this article refers to an inquiry into the normative significance of the interests revealed by implementation. How much to recognize competing interests is an open question depending on context. Governors blocking the doors of universities protecting white students from the unpleasant experience of black company is one thing. Nonhandicapped students wanting a good education, school teachers wanting to teach effectively, taxpayers wanting to save money, and school psychologists wanting normal working hours are different from racism and different from each other. In other words, interests competing with reformist goals in special education, as revealed by implementation, have a facial normative validity. They seem to be interests which should be taken seriously.

Recognizing the possible normative significance of counter-reformist implementation interests means evaluating them, not necessarily accepting them. Nothing about a political analysis compels adoption of the sociological fallacy which totally dismisses formal goals by concluding that all adjustments are necessarily good just because they happened. Some adjustments may seem clearly undesirable when viewed from almost any perspective other than that of the particular interest responsible for the adjustment. ${ }^{228}$ Furthermore, there is no reason to assume that all adjustments are inevitable. Based upon an understanding of the politics of what occurred, new political forces may be able to change the law itself or change the leverage of the existing law, for

225. The pervasive role of costs in judicial interpretations is evidence of this significance. See supra note 193 and accompanying text.

226. The main deferral mechanism of the EAHCA is the purely procedural definition of the substantive right. An appropriate education is that education which results from appropriate procedures. See supra notes $36 \& 193$.

227. See Wellington, History and Morals in Constitutional Adjudication (Book Review), 97 Harv. L. Rev. 326, 328-39 (1983) (judges interpreting complex statutes are engaged in particularistic lawmaking).

228. In a sense, evaluation may consist of advocates convincing a sympathetic but disinterested observer (e.g., a judge) or, in democratic terms, the "mainstream." Clune, supra note 2, at 91-93. 
example, by introducing new resources. ${ }^{229}$ Fatalism is no more the child of sociology than ethical nihilism.

Thus, this article is intended to offer a method of evaluation which steers a middle course between the ideological fallacy, which assumes the normative hegemony of reformist goals, and the sociological fallacy, which assumes the normative legitimacy of actual behavior. No formula or scientific procedure exists for the distinctly normative phase of this "method." Evaluation remains an ethical and democratic exercise, resting on normative argument and persuasion. Also, although the method steers a middle course between the two types of fallacy, the right conclusion is not necessarily a compromise lying precisely between reformist goals and political adjustments. Perhaps one side or the other has the better of the argument, in spite of the "normative fact" that both sides have socially legitimate positions. ${ }^{230}$

All the constituent elements of a political evaluation have now been discussed: a summary of the EAHCA implementation gap, an explanation of which political interests are responsible for the gap, a discussion of the limits of legalization as a policy instrument in a politicized environment, and an argument for reformist evaluation which is normatively sensitive to opposing political interests. The next two sections will use this method of evaluation to make some recommendations for further reform of the EAHCA. The evaluative mindset with which this task is approached might be called "pragmatic idealism." Compromises of the reformist goals are acceptable if they are made on behalf of the important competing considerations revealed by implementation and if they are not too extensive. Compromises made on behalf of unimportant or disreputable interests should be renounced. Very large compromises made on behalf of significant interests could theoretically require repeal of the legislation. In addition to these normative issues, there is also the problem of feasibility; many things disapproved of cannot be changed. Sometimes law must give way to power regardless of right. While public education is not renowned for its tyrants or moral monsters, rigid bureaucratic attitudes may frustrate reform. ${ }^{231}$

229. The improved effectiveness of Title I is traced in Kirst \& Jung, The Utility of a Longitudinal Approach in Assessing Implementation: A Thirteen Year View of Tille I, ESEA, 3 Ed. Eval. \& Pol. ANAL. $17-$ 34 (1980); see also M. Mclaughlin, Evaluation and Reform: The Elementary and Secondary EduCATION ACT Of 1965, TítLe I (1975).

230. The possibility of recognizing socially legitimate competing values while also exercising some independent judgment could be questioned. The problem is similar to the problem of individual consciousness and autonomy in structuralism and the relative autonomy of law in Marxism. See Heller, Structuralism and Critique, 36 Stan. L. Rev. 127 (1984); A. Hunt, The Theory, Method and Politics of Critical Legal Theory (Apr. 1984) (unpublished paper); see also supra note 7. Perhaps a more direct analogy is the difficulty of democratic institutions recognizing some emerging, marginalized interest which is incompatible with existing distributions of political rights, economic rights, and consciousness (especially given that all distributions of political rights are also distributions of economic rights, and vice versa). See Clune, supra note 7, at 764 n.7, 777-79; Tushnet, Talking to Each Other: Reflections on Yudof's When Government Speaks (Book Review), 1984 WIS. L. REv. 129. Practically speaking, evaluators can bring to bear some new combination of general knowledge, experience, new facts, and new values.

231. See P. BERman, supra note 195; see also the different regulatory issues raised by "bad apples vs. good apples" in E. BARDACH \& R. KAGAN, supra note 8, at 64-66. 


\section{B. EAHCA Evaluated: Is There Success After Implementation?}

An adequate foundation has now been established for EAHCA evaluation. The following discussion will attempt a summary of the successes and failures of the Act, looking not just at reformist legal purposes, but at the welfare of handicapped children generally and the legitimate interests of schools as revealed by implementation behavior. An attempt will be made to reach an overall evaluative position-which is intended to be realistic and sensitiveon the basis of this ledger sheet of successes and failures. Finally, section C discusses what remains to be done.

1. Summary of Successes and Failures. The EAHCA has achieved a number of notable successes. As is frequently true with social reform legislation, the most obvious and shocking problem with which the legislation was concerned-the complete exclusion of handicapped children from schools-was the most completely solved. There have also been successes in more subtle areas. Special education programs have been implemented on a massive scale, whether measured in terms of special classes, teacher aides, or new testing procedures. ${ }^{232}$ There also has been widespread use of the IEP; a new and rather expensive educational routine has been adopted almost everywhere. While formal compliance is better than substantive compliance (the IEP's are better than the programs they recommend) and parental effectiveness in the IEP process is questionable, schools seem to approve of the IEP as a pedagogical innovation. Some benefits are likely derived merely from improved organizational planning independent of effective parental participation or detailed compliance. Due process has not been a success in terms of informalist goals, but it has brought schools to a high degree of compliance at least in readily measurable legal requirements. The implementation of special education is also an impressive example of organizational adaptability and innovation. New organizational routines have been developed to cope with and make more effective each of the main types of legalism discussed in this article (pre-referral screening, IEP checklists, and due process mediation). Another triumph is the legion of mostly invisible adaptive educational innovations not specified in the law but developed in response to it by school people, parents, and advocates. Beyond all of these programs and procedures lies a

232. The special education system has grown dramatically over the past decade. In 1966, the total expenditures for "excess cost" on special education programs was $\$ 680$ million. Lynn, supra note 37, at 14. In 1972, the excess cost expenditures had risen to $\$ 2.7$ billion. G. BREWER \& J. KAKALIK, supra note 68 , at $392-93$. By 1978, that figure had grown to an estimated $\$ 7$ billion, and a comparable figure today may well be in excess of $\$ 10$ billion. See supra note 70 (the $\$ 10$ billion figure is estimated by multiplying the total number of currently served handicapped children by inflationadjusted cost figures for special education services). Similarly, the number of handicapped children served has grown. In 1966, approximately 2.1 million children received special education services. Lynn, supra note 37 , at 14. By 1981-82, that number had risen to 4.2 million. FifTH ANNUAL REPORT, supra note 51, at 90 . Finally, the number of special education teachers and other staff employed to serve handicapped students has grown sharply. In 1976-77, there were 179,804 special education teachers and 151,649 school staff employed to serve handicapped children. By 1980-81, those numbers had increased to 232,627 and 207,384 , respectively. Id. at 100-01. 
new era for handicapped children and their parents, an era of new opportunities, changed attitudes, and heightened responsiveness.

One of the conspicuous failures of the Act was the ideal of an individually appropriate education. What occurred instead was the establishment of routinized special programs. ${ }^{233}$ Individualized programs fell victim to lack of technical knowledge, budgetary constraints, and the needs of schools for routinized procedures. As organizations with many functions, schools must be able to plan for special education within a finite budget. The idea of a customized education for every handicapped child violated these fundamental organizational precepts.

Another casualty was the ideal of effective participation by individual parents. Individual effectiveness fell victim to a powerful quartet of forces: the continuing and paternalistic nature of the relationship between schools and families, an imbalance of litigation resources between the schools and parents, a lack of technical knowledge about the proper treatment for various handicaps, and a lack of program choices. The tiny number of parents who break through the bureaucratic, economic, and psychic barriers against litigation and actually get to an administrative hearing do respectably well. But if litigation succeeds, it does so through deterrence, not because it is a regular part of the process.

In addition to these two principal shortcomings, there have been many garden variety implementation problems, such as pockets of resistance, areas with especially poor programs, and so forth.

2. Evaluation of the Successes and Failures. By any comparative standard, the successes achieved in the implementation of special education have been truly impressive. Universal field level implementation of anything is quite rare. Most unsuccessful social reform programs either fail to get past the stage of symbolic politics, or fail to achieve any meaningful change of activity in the regulated organization. ${ }^{234}$ By comparison, special education laws have brought about a great deal of field level activity almost everywhere. The fact that this activity has not achieved some desirable goals should not detract from the fundamental picture of special education as a widely implemented program.

A stronger case can be made-that special education has approached the limits of realistic achievement. Looking at the pattern of implementation as a whole, one can ask how much more can be done for handicapped children given any fair claim on resources and existing state of knowledge about what can be done. Of course, a great many specific things need to be improved.

233. Cf. E. Krug, 2 The Shaping of the American High School 168, 196 (1972) (progressive, individualized education concept, when translated into use by the masses, led to standardized workbook, rather than individualized instruction); C. Washburn \& S. Marland, Winnetka: The History and Significance of an Educational Experiment $21-25,155$ (1963) (describing standardization of efforts to individualize self-instruction in arithmetic in Winnetka, Illinois public schools in the 1920 s, resulting in what are now known as workbooks).

234. On the typical range of implementation success, see Clune, supra note 2, at 87-89. 
But from a more global perspective, it appears that special education has obtained a significant amount of new resources for its clients, and that these resources have been used in reasonably efficient ways, given the limited knowledge base and what is reasonable to expect out of large scale bureaucratic organizations. What is reasonable to expect is, of course, partly a normative judgment. But the normative position is not strictly subjective. As discussed earlier, one of the salient features of the environment of special education is the high degree of moral legitimacy of many of the considerations competing with special education needs.

The impression of relative success is fortified by reference to implementation theory. Viewing the politics of implementation, special education seems to be a prototype of the successful implementation profile: a powerful constituency group well organized at both the national and local levels, with membership cutting across all economic classes. ${ }^{235}$ Discussion with education officials at almost any level of government confirms that the special education lobby is renowned for its political clout. Moreover, by and large, the EAHCA is an effectively devised law. IEP's and M-teams represented genuinely progressive educational innovations. Due process rights provided an important source of leverage, especially for advocacy groups bringing institutional litigation and for those individual families with enough motivation, skill, and resources to become litigants.

How then should the conspicuous failures of the Act be evaluated? The argument can be made that not only was the ideal of an individually appropriate education unrealistic, it was implicitly recognized as such in the legislation. ${ }^{236}$ For both budgetary and organizational reasons, school systems cannot operate on a truly individual basis, offering each student a separate program of instruction. Tutorial programs for every child would be exorbitantly expensive and parents' expectations of such an enormous shift of societal resources toward their handicapped children must be considered unrealistic. Even if the resources were available, existing technical knowledge does not allow precisely tailored programs for each child. Coarse programmatic categories are probably all that can be managed. Tutorial programs would be nice for handicapped children, but they would be nice for other children, too.

235. According to Sabatier and Mazmanian, conditions for an effective implementation include the following: clear standards, sufficient enforcement resources, a supportive regulatory agency, a limited number of parties whose consent is needed or who may veto, skillful leaders, active support by strong constituency groups, and lack of conflict with other programs or socioeconomic conditions. Sabatier \& Mazmanian, The Conditions of Effective Implementation: A Guide to Accomplishing Policy Objectives, 5 Pol'y Analysis 481, 484-500 (1979).

Michael Pertschuk suggests that six factors are responsible for successful public interest lobbying in Washington, D.C.: (1) a grass roots organization outside Washington; (2) involvement of public and private authorities to confirm the facts; (3) involvement of experienced Washington lobbyists and experts with networks of information; (4) help from political entrepreneurs in Congress; (5) help from a sympathetic and supportive corps of journalists; and (6) overreaching by the opposition (lies, outrageous conduct, etc.). Hesselberg, 'Lobbying Without Money': It's a Tough Job, Wis. St. J., July 8, $1983, \S 3$, at 1 .

236. See supra notes 36 \& 193. 
The lost ideal of effective parental participation evokes an equally ambivalent response. Perhaps it is possible to increase parental efficacy by providing all parents with more legal services. Exactly what good would be accomplished by such a large investment of resources is less clear. Most of the factors that limit parental control over results are substantive rather than procedural and therefore seem difficult to remedy. If schools must have relatively few rather routinized programs and organizational responses, the most that parents could do is choose between existing programs. If planning and budgeting of special education must be integrated with the rest of the functions of the school, parents cannot expect to be allowed to demand a totally new process of organizational planning at every stage of educational development. In other words, once all the necessary concessions are made to school functions, exactly what is left for parental control? Looming over all these questions is the nature of the school-parent relationship, which must be continuing, trusting, cooperative, and fundamentally paternalistic. Perhaps parental satisfaction could be markedly improved with increased legal services. Whether this is a goal appropriate for special education or worth the cost is debatable.

Overall, the failures of the Act seem to have occurred in areas relating to the individualistic ideal of liberal legalism, while the successes have been examples of collective and organizational problem solving. Indeed, the most forceful question which emerges from the implementation studies is whether those legalisms based on the ideal of individual parent participation-the IEP and due process rights-simply should be abandoned. They seem to produce little parental participation at considerable cost. Why not repeal these provisions, leaving such internal organizational routines as testing requirements and multi-disciplinary evaluation teams?

Although it is worth thinking about, the evidence does not support such a drastic change. Due process rights are not costly unless they are used, and they are used to good advantage by some parents and by advocacy groups seeking structural reform. Also, due process rights seem to have encouraged the widespread practice of informal mediation, thereby accomplishing indirectly the informalist goals intended for the administrative hearings themselves. Since IEP's are used all the time, even when parents do not participate, the case for dropping IEP's seems to be stronger. However, in our view, the IEP is the procedural keystone holding together all of the other requirements of the Act. The IEP serves as the prospective focus of the whole initial internal process of referral, assessment, and placement. It is the written expression of the entire set of organizational decisions that determine a child's treatment. Retrospectively, the IEP serves as the audit track for administrative hearings and government monitoring. Therefore, while all sorts of improvements in IEP's-even though making them burdensome and more substantive-may be welcome, abolishing the requirement of any written record of agency planning does not seem to be good idea. Moreover, regardless of how little most parents participate in organizational planning, the idea 
of abolishing the right to participate altogether seems somehow to be going in the wrong direction. If parents were not given the right to participate in something called an IEP conference, they would have to be given some other structural opportunity.

It does seem that the case for the IEP has the tenuous quality of the case for many legalisms; it seems sufficiently related to something important that, on balance, it is probably a good idea. There are really three justifications for the IEP: as a matter of internal organizational routine, the IEP forces schools to pay attention to the needs of the individual child; the IEP allows parent participation; and the IEP permits monitoring agencies to determine what has occurred. Each of these justifications is subject to the usual criticism of legalisms that it does not achieve the justifying objective either very directly or very well. Individual attention by the organization is diminished by limitations on available programs and routinization of referral and assessment. Parental participation is reduced by the relational factors discussed often and at length earlier in this article. Monitoring is not really a goal in itself (why monitor if the monitored activity is not doing any good in the first place?). Also, the effectiveness of monitoring in changing organizational behavior is in doubt because of the formalistic quality of administrative and judicial supervision.

Optimism about the IEP must rest ultimately on a somewhat intuitive set of judgments: in this sense, the scientific-sounding goal of an "appropriate education" is misleading. The best case for IEP's is probably that the needs of handicapped children are not well served by customary organizational routines and that even a small amount of special consideration can go a long way in a bureaucratic setting like schools. The benefits are surely spotty, and they come at considerable cost, but there is a net profit. However, collective discussion of such judgment calls is essential. Complex, normative/factual judgments are not scientific and are most valid when they reflect a variety of life experiences and normative perspectives. Positive evaluations can simply be the product of a gullible personality. Regardless of what the answer might be, inevitably there will be serious doubts.

\section{What Should Be Done Now: Is There Reform After Pragmatism?}

This is the last of the six elements specified in the introduction as parts of the political method of evaluation, and it is now possible to see the cumulative nature of those elements. The present discussion of reform rests on the five preceding discussions. Having struck a final balance and pondered feasible options, it is time to consider possible reforms.

A logical question emerging from the foregoing is the extent and nature of reforms which might be expected. Has there been such tolerance about system adjustments that there is no basis on which to demand change? On the contrary, concessions to the needs of bureaucratic rationality should not be interpreted as complacency or carte blanche approval of school behavior. The conclusion that the reform program has produced an overall justifiable equilibrium of various legitimately competing forces is perfectly consistent 
with a position that there are also many serious problems which should be and can be remedied. The key question answered by approval of system adjustments is whether to spend time trying to remedy what are seen as massive structural failures from the perspective of the original reformist purposes, or to concede that some of those failures were the consequence of unrealistic expectations and proceed to other, second generation problems revealed by a study of the actual implementation of the law.

The choice, in other words, is the familiar one between radical and reformist change. ${ }^{297}$ Since the EAHCA is, in its domain, a bold piece of progressive legislation, and since the opposing interests are valuable and legitimate, this article comes down firmly on the side of reformism. It seems that attention should be placed not on unrealized and unrealistic goals of the original legislation but rather on selected serious problems which have been uncovered by experience with the law, and for which there are known remedies. This kind of remedy is usually based on systematic knowledge about program implementation and is also structural in form, that is, the problem usually requires either legislation or institutional litigation. Not enough is known about special education to suggest either a complete list of such problems or a sense of priorities. Such knowledge typically must come from the community of researchers, experienced professionals, and advocates whose participation in research funding therefore becomes essential. ${ }^{238}$

Our own evaluation does suggest a number of possible reforms worth serious consideration, and these will serve as examples of the kind of remedy justified by the political evaluation just completed. Such reforms can be usefully divided into two categories: ways of improving the effectiveness of existing legal mechanisms, and means of providing for educational development and assistance. Attention should be paid, in other words, both to the legally institutionalized structure of interaction and the informal "underground" of educational practice.

In the first category, improvements in legal instruments, we suggest reforms of M-teams, IEP's, due process, and diagnostic categories. In many districts, M-teams do not function as they should. Instead of an interdisciplinary group of decisionmakers, special subsets of people participate in or control the team. ${ }^{239}$ Even in pragmatic terms, this is substandard. A properly

237. See Levin, Education and Work (Project Report 82B-8, Institute for Research on Educational Finance and Governance, Stanford University, 1982) (education contains a variety of both progressive and regressive aspects).

238. In an earlier draft, we referred to "structural remedies based on systemic knowledge." Although similar sounding, this is much different than Lindblom and Cohen's "professional social inquiry." C. Lindblom \& D. Cohen, Usable Knowledge 7 passim (1979). The core of knowledge about legal reform must come from participants (or those who talk with participants) and really is nothing more than collected, analytically ordered craft knowledge. Thus, we are talking about knowledge which is disciplined and systematic but is also "ordinary."

239. Study of Procedures, supra note 159, at 7.7 (it is often difficult to determine who makes a placement decision or when the placement decision is made; decision often reached by one or two staff members rather than team); A NATIONAL. SURvey of IEPs: Vol. 1, supra note 73, at 8-9 (Of the three mandated categories of participants in the IEP meetings-teachers, administrators, and parents-about one-third of all IEP meetings had all three classes of participants, although the study 
constituted M-team can at least provide the intended expert participation in the larger decisionmaking process. Excluding careful evaluation almost certainly conceals the availability of productive, pragmatic options. As for IEP's, the system also seems to have gone too far in the direction of formal compliance. ${ }^{240}$ Experimentation on ways to make IEP's conform better to actual programs, and vice versa, seems well worthwhile. More substantive review at the state level is a possible answer. (Of course, the prevalence of essentially illegal M-teams suggests that even formal compliance with the IEP process is far from perfect.) In the area of due process, a hard look at the use of parent advocates and the "communicative use of conflict" is surely justified. Claims have been made that such improved representation leads to better results, greater satisfaction, and a lower cost. ${ }^{241}$ What about reforming special education classifications? Some have urged abolishing the distinction between the learning disabled (LD) and educable mentally retarded (EMR) classifications. ${ }^{242}$ The success of special education programs is tied to high expectations for the children. Because the label EMR suggests a "retarded" child who cannot learn, EMR programs can become a dumping ground for all students, especially minority students. Abolishing the EMR category deserves serious consideration. 243

Of the two avenues for reform, improving educational practice is probably the more important because it has been the more neglected. We suggest three promising areas: the perennial problem of the "bad apple" district or school, the dissemination of successful and unsuccessful educational tech-

notes that this is probably an underestimate of the actual rate of participation by all concerned parties. By category, the study found that teachers participated about three-fourths of the time, parents two-thirds of the time, school administrators three-fifths of the time, and school counselors or psychologists about one-fourth of the time.); Bickel, supra note 91, at 194 (placement team meetings tend to be dominated by administrative personnel or psychologists); Panel on Selection and Placement of Students in Programs for the Mentally Retarded, Placement in Special Education: Historical Developments and Current Procedures, in Placing Children in Special Education: A Strategy for EQUITY 23, 39 (1982) ("Occasionally, school personnel meet in advance to iron out disagreements and present a united front to parents.") [hereinafter cited as Panel on Selection and Placement].

240. See supra notes $125-41$ and accompanying text.

241. See J. Handler, supra note 166.

242. For example, some experts have observed that:

On the basis of documented effective practice in schools to date, it appears that basically the same kind of instructional processes may be needed for LD children as for mildly mentally retarded children. It should be noted that there is at least one other large group of children with academic difficulties who do not acquire special education labels but who . . . by reason of low family income and poor performance on achievement tests are assigned to various compensatory education programs-usually in particular academic subjects for a part of each school day. The accumulating evidence about these children also suggests that the same features of direct, externally paced, and formally monitored instruction in academic content that have been noted for mentally retarded children produce the best learning results.

If these three theoretically distinct groups of children in academic difficulty seem to prosper best under the same kind of instruction, there is good reason for calling into question the traditional system of categorical labeling within special education. At the very least, the burden of proof seems now to lie with those who would defend the traditional divisions within special education.

See Panel on Selection and Placement, supra note 239, at 86-87.

243. By 1981, California had phased out EMR classes. Court Backs Ban of IQ Tests for Placing Mentally Retarded Children, 12 Sch. L. NEws I (Capitol Public. Jan. 27, 1984). 
niques, and the design of structures for participation by advocates in educational planning. In the theory of regulatory compliance, the bad apple is the regulated enterprise which will not cooperate with regulatory incentives-the stonewaller. ${ }^{244}$ Such enterprises are typically characterized by lack of willingness to comply or capacity to comply or both. ${ }^{245}$ Bad apples exist in the area of special education; there are districts and schools that do not accept the fundamental premises of the EAHCA and that respond to requests for change with obstinance. Resistant districts and schools are probably isolated from effective local advocacy groups and staffed with unenlightened leadership. In other words, they lack effective political pressure and leadership from either the community or school. How to identify and reform such organizations is unclear but well worth some serious thinking and research. One possibility which comes to mind is a special staff in state education agencies responsible for organizational development in the area of special education.

A second reform in the category of improved educational practice is the further dissemination of effective and ineffective educational techniques. Consistent with both the underground quality of educational practice and the extremely decentralized quality of organizational responses, compliance with the EAHCA is characterized by a great range of variety in responses. Some districts and schools do very well; others do poorly. Techniques of both effective and ineffective compliance also differ greatly. In this environment of low visibility information, recording and disseminating organizational responses is an important service. Funding by the National Institute of Education of this kind of research has produced encouraging results. ${ }^{246}$ Finally, research and development resources should be directed to the question of participation by special education advocates in educational planning. The perspective of implementation offered by this article strongly supports suggestions of greater participation, such as those made in another article in this volume. ${ }^{247}$ Implementation is primarily regarded as a process of integrating reformist objectives with organizational imperatives. In such a perspective, exclusion of advocates from the planning process reduces the efficiency of their participation. Advocates must react to existing policy as well as making creative suggestions in the formation of new policy. ${ }^{248}$

Expectations for the entire package of recommended reforms should be

244. See supra note 156 .

245. See supra note 195 .

246. See Kimbrough \& Hill, supra note 213.

247. See Sindelar, How and Why the Law Has Failed: An Historical Analysis of Services for the Retarded in North Carolina and a Prescription for Change, LAW \& Contemp. Probs., Spring 1985, at 125.

248. The twin hazards blocking effective representation of outside interests within a bureaucracy are cooptation and selling out. The trick, therefore, is to institutionalize access while protecting new values. See C. Stone, Where The Law Ends: The Social Control of Corporate Behavior 120 (1975); S. Taylor, Making Bureaucracies Think: The Environmental Impact Statement Strategy of Administrative Reform (1984). In the proper circumstances, this combination of power and priority, access and clout, may be provided by a legislator well connected with the bureaucracy, someone whom Eugene Bardach calls the implementation "fixer." E. Bardach, supra note 8 , at 273-78. A judge in institutional litigation may function in much the same way as this legislative "angel." See Clune, supra note 191, at 70. 
kept modest, even in the unlikely event that they all are successfully enacted and implemented. Unlike Professor Handler, for example, we do not regard any of these reforms as resolving fundamental contradictions between individual participation and organizational imperatives. ${ }^{249}$ Handler's recommendations might result in a favorable shift in that balance toward the individual. But the process will still be one of compromise, with results heavily weighted toward the more powerful collective interests. Regardless of how effective a role parents can be given in administrative hearings, for example, very few will challenge organizational decisions. The same obstacles that limit effectiveness now would limit effectiveness then: the trusting, ignorant, dependent relationship; lack of litigation resources and financial incentives for victory; and recognition by hearing officers and judges of organizational interests in the substance of their decisions. Changes might be valuable, but they are certain to be marginal.

\section{Conclusion: Evaluation as a Continuing, Democratic Process}

The method of social program evaluation recommended in this article urges that the political adjustments of implementation be taken seriously as normative events. Instead of looking at reformist goals alone, consideration should also be given to the organizational and financial costs of those goals and their feasibility, as revealed by the process of implementation. Following this method one discovers not a law that has failed, but a law that has been the subject of any number of compromises and adjustments, some reasonable, some not.

Do reformist goals therefore become completely outmoded, to be replaced by the more sophisticated political analysis? Interestingly enough, the answer is clearly no, because of the aspirational function of reformist goals. Even sophisticated reformers who understand that a literal realization of program goals would be impossible, and perhaps undesirable, need to maintain the credibility of the goals as ideals. The ideal of an "appropriate education" for every child, while literally impossible, is nevertheless important as a means of pushing systems incrementally closer to the ideal. Appropriate education must retain the form of a legal requirement if it is to have any use as an entitlement in negotiations. ${ }^{250}$ In order to ask for progress,

249. Handler accurately exposes the helplessness of the dependent individual as the adversary of the group; but, in the end, he must concede the dangers of cooptation which are implicit in the group as protector of the individual. See J. HANDLER, supra note 166 , at $\mathrm{ch}$. 6 . Thus, contradictions within the liberal legalist paradigm of adversarial individualism can be softened but not completely transcended.

250. The precise role for formalism in all of this is elusive. Advocates are likely to make the formalistic argument that the law means an absolute right (which the advocate is entitled to compromise on behalf of the good of the client), rather than the more overtly sociological argument that the law gives the advocate de facto capacity to pester the school on the authority of a vague requirement which could produce adverse results in court. Actually, such sharp distinction is not so apparent. 
reformers must characterize systems as failing to meet their ideals, even if, on the whole, the systems have been reasonable. Absolutism is an essential component of effective advocacy; advocates have no choice but to reject compromise, at least as an opening position in bargaining ("this child has an absolute right to an appropriate education, but we'll take the best you can do"). Legal rights must be absolute in form in order to be compromised in practice.

If sociological analysis cannot replace ideological advocacy, the question arises how to combine both in practice, or which one to follow if a choice is necessary. The two systems of evaluation are bound to reach different evaluative conclusions. So which is right? In the abstract, both positions are right in the sense that we always need both sides of a basic argument. The overall question of evaluation can never be finally settled. Advocates and realists will inevitably clash over what is right and what is feasible. Neither position can be awarded a final victory because both represent legitimate goals competing for scarce resources. But double vision is not required in judging particular controversies. After listening to both sides, a decisionmaker, such as a judge or a scholar, must decide which side has the better of the argument.

In this article, one of the things that we have done is reached a judgment about the overall success of the Act, implicitly rejecting what may prudentially be regarded as a partisan advocacy perspective-the idea of the EAHCA as a "total failure." By the logic of our own analysis, we are bound to differ with at least some advocates in this respect. However, the political method of evaluation does not automatically legitimate the status quo. Sometimes it cuts in exactly the opposite direction. An examination of implementation patterns may well reveal that regulated institutions in fact have not been doing their best. Some "adjustments," such as stonewalling on compliance with an administrative or judicial order, to take only the most obvious example, do not look good upon closer examination. Implementation studies may well prove so shocking that they galvanize a whole new round of legal reform. ${ }^{251}$ Judges who are timid in granting legal rights might well be more bold if they understood the practical limits of implementing rights. ${ }^{252}$ Far from diminishing and relativizing a legal right, sociological analysis may strengthen it.

In a sense, an amendment to recent literature on statutory interpretation is being recommended. When a statute is vague on a disputed point, it has been suggested that judges take into account community values, the conflicting political positions of statutory structure and legislative history, and the dictates of good public policy. ${ }^{253}$ This article suggests inclusion of implementa-

\footnotetext{
The words "appropriate education" have an idealistic and inchoate element as part of their meaning. Advocates make idealistic normative arguments as part of the contest over what the words should mean in practice. Prior to judicial interpretation, the meaning of the law is indeterminate, and each side must consider the risk of this uncertainty as part of litigation strategy.

251. The improved effectiveness of Title $I$ is traced in Kirst \& Jung, supra note 229.

252. See Comment, Compensatory Educational Services and the Education for All Handicapped Children Act, 1984 Wis. L. REv. 1469, 1514-26 (compensatory services not an excessive threat to school authorities because of practical imbalances in the legalized bargaining positions of schools and parents).
}

253. See G. Calabresi, A Common Law for the Age of Statutes (1982); Posner, Statutory Inter- 
tion politics on this list. Adjustments hammered out in the real world of budgets, organizational constraints, and precious self-interests may tell a great deal more about competing value positions than the abstracted purposes of laws.

Judges in fact seem to behave in the manner recommended. Judicial decisions during implementation about the meaning of a statute, constitution, or administrative rule are best seen as implementation compromises of the same sort as made by the bureaucracy. Notwithstanding the apparently independent cognitive process of seeking the "true meaning of the law," courts are actors in the democratic process of implementation, rather than transcendental forces above or outside it. Judges inherit the ordinary disputes of implementation with all the social legitimacy possessed by participants in such controversies. Discretion allowed by vagueness in doctrine is adjusted so as to produce politically sensible results. For the sake of true democracy, one hopes that judges respond to idealism as well as expediency.

Thus, for three reasons, no evaluation can ever be final or objective: first, evaluative standards are debatable and depend upon political location; second, perceptions of implementation facts shift with new information and new interpretive mindsets; third, evaluation is a democratic process rather than a scientific exercise. ${ }^{254}$ We certainly hope that this article has been a contribution to the democratic evaluation of the EAHCA; but, again, no evaluation can be the last word.

pretation-in the Classroom and in the Courtroom, 50 U. CHI. L. REv. 800, 817 (1983); Wellington, supra note 227 , at $328-29$.

254. Courts are part of the democratic process in two senses: applying legislative acts in specific situations, and making their own democratic decisions overruling an undemocratic legislature. See Clune, supra note 7; Wellington, supra note 227. 